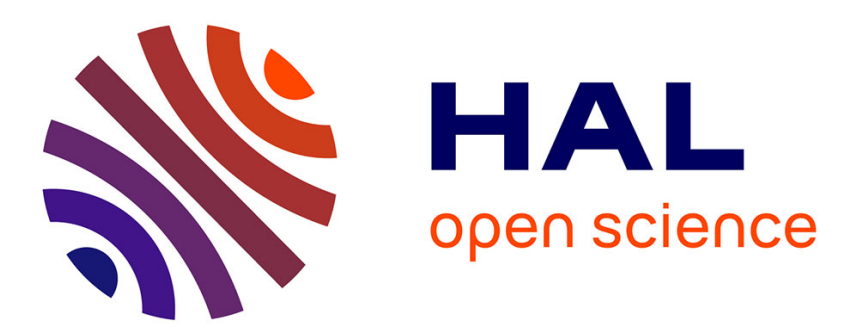

\title{
REDD1 deficiency protects against nonalcoholic hepatic steatosis induced by high-fat diet
}

Karine Dumas, Chaima Ayachi, Jérôme Gilleron, Sandra Lacas-Gervais, Faustine Pastor, François Bertrand Favier, Pascal Peraldi, Nathalie Vaillant, Laurent Yvan-charvet, Stéphanie Bonnafous, et al.

\section{To cite this version:}

Karine Dumas, Chaima Ayachi, Jérôme Gilleron, Sandra Lacas-Gervais, Faustine Pastor, et al.. REDD1 deficiency protects against nonalcoholic hepatic steatosis induced by high-fat diet. FASEB Journal, 2020, 34 (4), pp.5046-5060. 10.1096/fj.201901799RR . hal-02525977

\section{HAL Id: hal-02525977 \\ https://hal.science/hal-02525977}

Submitted on 7 Dec 2020

HAL is a multi-disciplinary open access archive for the deposit and dissemination of scientific research documents, whether they are published or not. The documents may come from teaching and research institutions in France or abroad, or from public or private research centers.
L'archive ouverte pluridisciplinaire HAL, est destinée au dépôt et à la diffusion de documents scientifiques de niveau recherche, publiés ou non, émanant des établissements d'enseignement et de recherche français ou étrangers, des laboratoires publics ou privés. 


\section{REDD1 deficiency protects against non-alcoholic hepatic steatosis induced by high fat diet}

Karine Dumas ${ }^{1}$, Chaima Ayachi ${ }^{1, *}$, Jerome Gilleron ${ }^{1}$, Sandra Lacas-Gervais ${ }^{2}$, Faustine Pastor ${ }^{1}$, François

B. Favier ${ }^{3}$, Pascal Peraldi ${ }^{4}$, Nathalie Vaillant ${ }^{5}$, Laurent Yvan-Charvet ${ }^{5}$, Stéphanie Bonnafous ${ }^{6,7}$, Stéphanie Patouraux ${ }^{6,7}$, Rodolphe Anty ${ }^{6,7}$, Albert Tran ${ }^{6,7}$, Philippe Gual ${ }^{6}$, Mireille Cormont ${ }^{1}$, JeanFrançois Tanti ${ }^{1}$, Sophie Giorgetti-Peraldi ${ }^{1, \#}$

1. Université Côte d'Azur, Inserm, C3M, Team « Cellular and Molecular Physiopathology of Obesity », France

2. Université Côte d'Azur, Centre Commun de Microscopie Appliquée, CCMA, France

3. Université Montpellier, INRA, DMEM, France

4. Université Côte d'Azur, Inserm, CNRS, iBV, Team “Stem cells and differentiation”, France

5. Université Côte d'Azur, Inserm, C3M, Team « Haematometabolism in diseases», France

6. Université Côte d'Azur, Inserm, C3M, Team « Chronic liver diseases associated with steatosis and alcohol», France

7. Université Côte d'Azur, CHU, Inserm, C3M, Team «Chronic liver diseases associated with steatosis and alcohol», France

*. present address: Université Côte d'Azur, Inserm, CNRS, iBV, Team “Diabetes Genetics”, France

\# Corresponding author: Sophie Giorgetti-Peraldi, Inserm U 1065, Centre Méditerranéen de Médecine Moléculaire (C3M), Bâtiment ARCHIMED, 151 route Saint Antoine de Ginestière, BP 2 3094, 06204 Nice cedex 3, France, phone (33) 4890642 29, e-mail : Sophie.GIORGETTI-PERALDI@inserm.fr

\section{Declarations of interest: none}


Short running title: Loss of REDD1 protects against hepatic steatosis 
Abbreviations: REDD1: Regulated in development and DNA damage response-1, mTORC1: mechanistic target of rapamycine complex 1 


\section{Abstract}

Non-alcoholic fatty liver disease is a chronic liver disease which is associated with obesity and insulin resistance. We investigated the implication of REDD1 (Regulated in development and DNA damage response1), a stress-induced protein in the development of hepatic steatosis.

REDD1 expression was increased in the liver of obese mice and morbidly obese patients, and its expression correlated with hepatic steatosis and insulin resistance in obese patients.

REDD1 deficiency protected mice from the development of hepatic steatosis induced by high-fat diet (HFD) without affecting body weight gain and glucose intolerance. This protection was associated with a decrease in the expression of lipogenic genes, SREBP1c, FASN and SCD-1 in liver of HFD-fed REDD1-KO mice. Healthy mitochondria are crucial for the adequate control of lipid metabolism and failure to remove damaged mitochondria is correlated with liver steatosis. Expression of markers of autophagy and mitophagy, Beclin, LC3-II, Parkin, BNIP3L, was enhanced in liver of HFD-fed REDD1-KO mice. The number of mitochondria showing colocalization between LAMP2 and AIF was increased in liver of HFD-fed REDD1-KO mice. Moreover, mitochondria in liver of REDD1-KO mice were smaller than in WT. These results are correlated with an increase in PGC-1 $\alpha$ and CPT-1 expression, involved in fatty acid oxidation. In conclusion, loss of REDD1 protects mice from the development of hepatic steatosis.

Keywords: REDD1, obesity, hepatic steatosis, autophagy 


\section{INTRODUCTION}

Non-alcoholic fatty liver disease (NAFLD) is a chronic liver disorder affecting up to $28 \%$ of adult European population. NAFLD can progress from simple hepatic steatosis (or non-alcoholic fatty liver, NAFL) defined as triglyceride accumulation in the liver, to more severe stages of non-alcoholic steatohepatitis (NASH) characterized by liver inflammation, hepatocellular injury and apoptosis (1-3). Hepatic steatosis is strongly associated with obesity and its complications, insulin resistance and dyslipidemia. Excessive lipid accumulation in the liver results from several mechanisms. Uptake of non-esterified free fatty acid (NEFA) released by adipose tissue and de novo lipogenesis regulated by the transcription factors SREBP-1c and ChREBP are increased. On the other hand, the lipid export in very low-density lipoproteins is reduced and fatty acid betaoxidation is decreased due to mitochondrial dysfunction. This is associated with the presence of megamitochondria in hepatocytes owing to mitophagy defects (4-8). Endoplasmic Reticulum (ER), oxidative, inflammatory, and genotoxic stresses have been detected in steatotic livers and are involved in the initiation and/or progression of NAFLD (9). Hence, key stress-regulated proteins may play a pivotal role in the pathogenesis of hepatic steatosis and NAFLD.

REDD1 (Regulated in development and DNA damage response-1, also known as DDIT4: DNA Damage inducible transcript 4) is an intracellular protein whose expression is regulated by several cellular stresses known to be increased in tissues during obesity including hypoxia, DNA damage and Endoplasmic Reticulum (ER) stress (10-13). In addition, REDD1 expression is also increased by hyperinsulinemia, hyperglycemia, dyslipidemia, and glucocorticoid, which are conditions induced by obesity (14-17). The best-known function of REDD1 is to inhibit the activity of mTORC1 by positively regulating the tuberous sclerosis complex (TSC), an upstream repressor of mTORC1. One proposed mechanism is to favor the dephosphorylation and inactivation of AKT by the protein phosphatase PP2A, preventing the inhibitory effect of AKT on TSC2 (18). It has also been shown that REDD1 sequesters 14-3-3 proteins allowing the inhibition of mTORC1 by TSC2 (19). By regulating mTORC1 and AKT, REDD1 is involved in several cellular processes including protein synthesis, cell growth, and autophagy. However, REDD1 can also mediates cellular effects independently of mTORC1 regulation. Indeed, REDD1 induces autophagy through mTORC1 dependent and independent mechanisms (20). In addition, we showed that REDD1 regulates MAP kinase, NF-kB, and inflammasome activation in bone marrow derived macrophages through mTORC1 independent mechanisms (21). Moreover, a role of REDD1 in the regulation of mitochondrial function, oxidative capacity, and ROS production has been proposed $(10,20$, 
22, 23). A pool of REDD1 is present at mitochondria and it was recently reported that REDD1 localizes in the mitochondria-associated membranes (MAMs) that allow communication between the ER and the mitochondria $(23,24)$.

The AKT-mTORC1 axis, as well as the mitochondrial fitness, play a central role in the regulation of glucose and lipid metabolism and insulin sensitivity. Emerging evidences suggest that REDD1 plays a regulatory role in insulin action and lipid metabolism (25). REDD1 in MEF cells inhibits insulin-induced T308-AKT phosphorylation (18). Likewise, REDD1 expression is increased in muscles of patients with T2D (Type-2 Diabetes) during an hyperinsulinemic-euglycemic clamp and may contribute to the development of insulin resistance (15). By contrast, loss of REDD1 in mouse plantar flexor muscles led to reduced insulin-stimulated IRS-1 tyrosine phosphorylation (26). We showed that the silencing of REDD1 expression in 3T3-L1 adipocytes inhibits insulin signaling and insulin-induced lipogenesis while others showed that REDD1 over-expression increases adipocyte lipolysis $(27,28)$. REDD1 may also control lipid metabolism by regulating mitochondrial abundance an oxidative capacity. In muscle, lack of REDD1 decreases the mitochondrial oxidative capacity and reduces exercise capacity (20). By contrast, increased REDD1 expression in liver of mice with a genetic deletion of Cathepsin $S$ is associated with a reduced activity of the mitochondrial respiratory chain (29). However, little is known regarding the role of hepatic REDD1 in the pathogenesis of steatosis and NAFLD associated with obesity.

To address this question, we studied REDD1-deficient mice in the context of diet-induced obesity. We found that REDD1 expression is increased in steatotic liver of obese mice and humans and that REDD1 deficiency prevents the development of hepatic steatosis without affecting body weight gain and insulin resistance development. Mechanistically, REDD1-deficient mice have a decrease in de novo hepatic lipogenesis and an increase in hepatic mitophagy leading to the presence of smaller mitochondria. 


\section{MATERIALS AND METHODS}

Materials: Antibodies were obtained from Santa Cruz Biotechnologies (Heidelberg, Germany): FASN sc20140, ERK2 sc-1647, HSP90 sc-13119, Beclin sc-11427, Parkin sc-32282, Pink1 sc-517353, Bnip3L sc166332; Cell Signaling Technology (Beverly, MA): AKT- pT308 \#13038, AKT- pS473 \#4058, AKT \#9272, ERK \#4695, pULK-S757 \#14202, S6-pS235/236 \#4856, S6 \#2317, 4E-BP1-pT37-46 \#9459; AIF (CST\#5318P) Proteintech (Chicago, IL): REDD1 \#10638-1-AP; Sigma-Aldrich: tubulin \#T6199; Adipogen: NLRP3 \#AG-20B-0014; Abcam: CPT1 \#ab128568, LAMP2 \#ab13524; Novus Biology: LC3 \#NB100-2220; Progen: p62 \#GP62C.

The primer sets for real time quantitative PCR were purchased from Eurogentec (Seraing, Belgium) and Qiagen (Courtaboeuf, France).

\section{Animal studies}

Mice: Whole-body REDD1 null mice (REDD1-KO) were generated by Lexicon Genetics Inc. (The Woodlands, TX) specifically for Quark Pharmaceuticals Inc. (Fremont, CA) and are the property of Quark Pharmaceuticals Inc. REDD1-KO and WT littermates mice were generated from C57BL/6J backcrosses (9 generations). To minimize genetic drift, backcross of the parental strain was performed every 10 generations. Mice were housed in standard cages with free access to food and water under $12 \mathrm{~h}$ dark-light cycle. The Principles of Laboratory Animal Care (NIH publication "Guide for the care and use of laboratory animals" $8^{\text {th }}$ edition, (https://grants.nih.gov/grants/olaw/guide-for-the-care-and-use-of-laboratory-animals.pdf) were followed, as well as the European Union guidelines on animal laboratory care (http://ec.europa.eu/environment/chemicals/lab_animals/legislation_en.htm). All procedures were approved by the Animal Care Committee of the Université Côte d'Azur and the French ministry (Ministère de l'éducation nationale, de l'enseignement supérieur et de la recherche), France (\#2015051914373792_v2).

Metabolic characterization: Male 8-week-old mice were fed with a normal chow diet (NCD) (Safe diet A04, $8 \%$ calories from lipid) or a high-fat diet (HFD) (ssniff® DIO-60\% calories from fat) for 25 weeks. Mice weight and food intake were monitored twice a week. For glucose tolerance test (GTT), fasted mice (16 h) were injected intraperitoneally with glucose solution ( $1 \mathrm{~g} / \mathrm{kg}$ body weight). Blood glucose level was measured using a glucometer before and after injection at the indicated times (FreeStyle Optium, Abbott Laboratories, Abbott Park, USA). Fasted (16 h) serum insulin, and NEFAs were measured using an HTRF-based (Cisbio, Codolet, France) or biochemical assay (Diasys, Holzheim, Germany), respectively. 
Mice metabolism was analyzed by indirect calorimetry to determine oxygen consumption (VO2) and carbon dioxide production (VCO2), energy expenditure (EE), respiratory exchange ratio (RER), and total activity using calorimetric tides cages (Oxyletpro-Physiocage Panlab, Bioseb, Vitrolles, France). Mice were individually housed and acclimated for $24 \mathrm{~h}$ before experimental measurements. VO2 and VCO2 were measured (Oxylet; Panlab-Bioseb, Vitrolles, France) in individual mice fed with normal chow diet or HFD at 32-min intervals during a fasted night period followed by unrestricted access on food period. The respiratory exchange ratio was calculated and analyzed as follows: $\mathrm{RER}=\mathrm{VCO} 2 / \mathrm{VO} 2, \mathrm{RER}=1$ corresponds to carbohydrate oxidation and RER 0.7 corresponds to fat oxidation. Energy expenditure (in kcal/day $/ \mathrm{weigh}^{0.75}=$ $1.44 \mathrm{X}$ VO2 X [3.815 + 1.232 X RER]) was calculated and ambulatory activities of the mice were monitored by an infrared photocell beam interruption method (Oxylet; Panlab-Bioseb, Vitrolles, France). All data were analyzed using 2 way ANOVA multiple comparison test in GraphPrism software.

Biochemical analysis: Serum alanine transaminase (ALT) and aspartate transaminase (AST) levels were determined as previously described (30). Hepatic triglycerides were determined using a Triglycerides FS 10' kit (Diasys, Holzheim, Germany). $\beta$-hydroxybutyrate was determined using Biosentec kit and Mindray analyzer.

Histological analysis: After 25 weeks of diet, mice were sacrificed in fed conditions by intraperitoneal injection of dolethal. Tissue were flash frozen in liquid nitrogen and stored at $-80^{\circ} \mathrm{C}$ until used. Alternatively, tissue were fixed in Roti-Histofix (Roth, Lauterbourg, France), embedded in paraffin, sectioned ( $7 \mu \mathrm{m}$ thick), stained with hematoxylin and eosin (H\&E) and imaged on a Zeiss PALM MicroBean system. Score of steatosis was performed as previously described (31).

Liver tissue embedded in OCT were sectioned (20 $\mu \mathrm{m}$ thick), stained with Oil Red O solution (3g/l in 60\% isopropanol) and imaged on a Zeiss PALM MicroBean system.

Western blot analysis: Tissues were solubilized using Precellys tissue homogenizer in ice-cold buffer containing $50 \mathrm{mmol} / \mathrm{l}$ Tris pH7.5, $150 \mathrm{mmol} / \mathrm{l} \mathrm{NaCl}, 0.1 \%$ SDS, $1 \%$ NP40, 0.5\% Na Deoxycholate, $2 \mathrm{mmol} / \mathrm{l}$ Orthovanadate, $5 \mathrm{mmol} / \mathrm{l} \mathrm{NaF}, 2.5 \mathrm{mmol} / 1 \mathrm{Na}_{4} \mathrm{P}_{2} \mathrm{O}_{7}$ and Complete protease inhibitor cocktail (Roche Diagnostics, Meylan, France).

Lysates were centrifuged $(14,000 \mathrm{rpm})$ for $10 \mathrm{~min}$ at $4^{\circ} \mathrm{C}$, and the protein concentration was determined using BCA protein assay reagent (Thermo Fisher Scientific, Brebières, France). Cell lysates were analyzed by Western blot. Immunoblots were revealed using PXi4 GeneSys imaging system. Quantifications were realized using MultiGauge or Fiji softwares (32). 
Real-time quantitative PCR analysis in mice tissue: RNA was isolated from tissues (TRIZOL, Invitrogen), and cDNA was synthesized using Transcriptor first strand cDNA synthesis kit (Roche Diagnostics, Meylan, France). Real-time quantitative PCR was performed with sequence detection systems (StepOne Plus Real-time PCR system (Thermo Fisher Scientific Inc.) and SYBR Green dye. Gene expression values were calculated based on the comparative cycle threshold $\mathrm{Ct}$ method $\left(2^{-\Delta \Delta C t}\right)$. Levels of mRNA were normalized to the expression value of the housekeeping gene RPLP0 and expressed relative to the mean of the group of controls. The following primers were obtained from Qiagen (Courtaboeuf, France): CD36 \#PPM03796D-200; FASN \# PPM03816E-200 ; NOS2 \# PPM02928B ; ARG \# PPM31770C. The following primer sequences were used REDD1 (AGGAAGAGGAGGACGAGAAACG/ CGCCTTCATTCGGACCTTAG), Plin-1 (GGCCTGGACGACAAAACC/CAGGATGGGCTCCATGAC), ApoB (TTCTTCTCTGGAGGGGACTG / GGCACTGTGGGTCTGGAT), SREBP1c (GCTTCCAGAGAGGAGGCCAG / GGAGCCATGGATTGCACATT ), SCD-1 (CGGAGACCCCTTAGATCGA / TAGCCTGTAAAAGATTTCT ), Insig2a (TGTGAAGTGAAGCAGACCAATGT / CCCTCAATGAATGTACTGAAGGATT ), DEC-1 (TTGTCGGGAAGAAATCTCGAG-GCA / AGTGTTCTCATGCTTCGCCAGGTA ), PGC1 $\alpha$ (GGA ATATGGTGATCGGGAACA / AAAGGATGCGCTCTCGTTCA ), CCL2 (GCATTAGCTTCAGAT TTACCGGT / TTAAAAACCTGGATCGGAACCAA ), IL1 $\beta$ (TCGCTCAGGGTCACAAGAAA / C ATCAGAGGCAAGGAG GAAAAC ), RPLP0 (CTTTATCAGCTGCACATCACTCA / TCCAGG CTTTGGGCATCA ).

Electron microscopy: For ultrastructural analysis, tissues were fixed in $2.5 \%$ glutaraldehyde in $0.1 \mathrm{M}$ cacodylate buffer $\mathrm{pH} 7.4$ at $4{ }^{\circ} \mathrm{C}$, rinsed in $0.1 \mathrm{~mol} / \mathrm{l}$ cacodylate buffer, post-fixed for $2 \mathrm{~h}$ in $1 \%$ osmium tetroxide and $1 \%$ potassium ferrocyanide in $0.1 \mathrm{~mol} / \mathrm{l}$ cacodylate buffer to enhance the staining of membranes. Cells were rinsed in cold distilled water, quickly dehydrated in cold ethanol and lastly embedded in epoxy resin. Contrasted ultrathin sections $(70 \mathrm{~nm})$ were analyzed under a JEOL 1400 transmission electron microscope (EM) mounted with a Morada Olympus CCD camera.

Immunofluorescence: Fixed liver tissue embedded in OCT were sectioned (10 $\mu \mathrm{m}$ thick), and permeabilized with $0.2 \%$ Tween- 20 for $10 \mathrm{~min}$ at room temperature. The sections were incubated with antibodies directed to AIF and LAMP2 followed by fluorescently labeled secondary antibodies, DAPI (Sigma D9542) and Alexa Fluor 488-Phalloidin (Invitrogen\#A12379). 
5 images for each mouse (10 mice per group) were randomly acquired using Nikon A1R confocal microscope and analyzed using Fiji software using the same parameters for each image. To avoid mistakes in the analysis, images in which more than 50 mitochondria were detected were conserved for quantification.

\section{Human studies}

Morbidly obese patients: Morbidly obese patients $(n=20)$ were recruited through the Department of Digestive Surgery and Liver Transplantation (Archet 2, University Hospital, Nice, France) where they underwent bariatric surgery for their morbid obesity. Bariatric surgery was indicated for these patients in accordance with French guidelines. Exclusion criteria were: presence of hepatitis B or hepatitis $\mathrm{C}$ infection, excessive alcohol consumption ( $>20 \mathrm{~g} / \mathrm{d}$ ) or another cause of chronic liver disease as previously described (33-35). The characteristics of the study groups are described in Table 1. Before surgery, fasting blood samples were obtained and used to measure alanine transaminases (ALT), glucose, insulin and HbA1c. Insulin resistance was calculated using the homeostatic model assessment (HOMA-IR) index (36). Surgical liver biopsies were obtained during surgery and no ischemic preconditioning was performed. Hepatic histopathological analysis was performed according to the scoring system of Kleiner et al. (37). Four histopathological features were semi-quantitatively evaluated: grade of steatosis $(0,<5 \% ; 1,5 \%-30 \% ; 2,>30 \%-60 \% ; 3,>60 \%)$, lobular inflammation ( 0 , no inflammatory foci; $1,<2$ inflammatory foci per 200x field; 2, 2-4 inflammatory foci per 200x field; $3,>4$ inflammatory foci per 200x field) and hepatocellular ballooning ( 0 , none; 1 , few balloon cells; 2 , many cells/prominent ballooning). All subjects gave their informed written consent to participate in this study in accordance with French legislation regarding Ethics and Human Research (Huriet-Serusclat law). The “Comité Consultatif de Protection des Personnes dans la Recherche Biomédicale de Nice" approved the study (07/04:2003, $\left.\mathrm{N}^{\circ} 03.017\right)$.

Real-time quantitative PCR analysis in human tissue: Total liver RNA was extracted using the RNeasy Mini Kit (74104, Qiagen, Hilden, Germany) and treated with Turbo DNA-free DNase (AM 1907, Thermo Fisher Scientific Inc.) following the manufacturer's protocol. The quantity and quality of the RNA samples were determined using the Agilent 2100 Bioanalyzer with RNA 6000 Nano Kit (5067-1511, Agilent Technologies, Santa Clara, CA, USA). Total RNA $(1 \mu \mathrm{g})$ was reverse transcribed with the High-Capacity cDNA Reverse Transcription Kit (Thermo Fisher Scientific Inc.). Real-time quantitative PCR was performed in duplicate for each sample using the StepOne Plus Real-Time PCR System (Thermo Fisher Scientific Inc.) as previously described $(38,39)$. TaqMan gene expression assays were purchased from Thermo Fisher Scientific Inc.: RPLPO (Hs99999902_m1); REDD1 (Hs00430304_g1). Gene expression was normalized to the RPLP0 (Ribosomal 
Phosphoprotein Large P0) housekeeping genes and calculated based on the comparative cycle threshold $\mathrm{Ct}$ method $\left(2^{-\Delta \Delta C t}\right)$.

Statistical analysis: Data are expressed as the mean +/- SEM. Statistical analysis was performed using GraphPad Prism version 7.00 for Windows, (GraphPad Software, La Jolla California USA). Differences among groups were compared using ANOVA with post-hoc analysis for multiple comparisons and Mann-Whitney test when there were only two groups. $p$ value $<0.05$ is considered as significant. ${ }^{*} \mathrm{p}<0.05 ; * * \mathrm{p}<0.01 ;{ }^{* * *} \mathrm{p}<0.001$; $* * * * \mathrm{p}<0.0001$ 


\section{RESULTS}

\section{REDD1 expression is increased in liver during obesity}

We first determined whether hepatic REDD1 expression was modulated in liver of HFD-fed obese mice. REDD1 mRNA and protein expression was increased in the liver of HFD-fed mice characterized by the presence of lipid droplets compared to NCD-fed mice (Figure 1A).

To determine whether hepatic steatosis was also associated with an increase in hepatic REDD1 expression in humans, we investigated the expression of REDD1 mRNA in liver biopsies from morbidly obese patients without or with NAFL (Table 1). REDD1 mRNA expression was increased in liver of obese patients with NAFL ( $n=15)$ compared to patients with obesity but without NAFLD ( $n=5$, Figure 1B). Importantly, REDD1 mRNA expression was positively correlated with the percent of steatosis (Figure 1C). Moreover, a positive correlation was found between hepatic REDD1 mRNA and insulin resistance measured by homeostasis model assessment (HOMA-IR) in patients with comparable BMI (Figure 1C).

\section{REDD1 deficiency prevents HFD-induced hepatic steatosis independently of obesity and insulin resistance}

To investigate whether the increase in hepatic REDD1 expression plays a role in the pathogenesis of obesityinduced fatty liver, we challenged WT and REDD1-KO mice with HFD for 25 weeks. The absence of REDD1 in liver was verified by RT-qPCR and western blot analysis (Figure S1A-B). No obvious difference on body weight at the end of the diet, body weight gain during the diet, and food intake was observed between WT and REDD1-KO mice fed with NCD or HFD (Figures 2A, S2A-B). Moreover, there was no significant difference between the two genotypes in oxygen and $\mathrm{CO}_{2}$ consumption, energy expenditure, respiratory exchange ratio (RER), and total activity both on NCD and HFD (Figure S2C-F). Upon HFD, WT and REDD1-KO mice developed the same level of glucose intolerance on IP-GTT with a similar increase in fasted and fed serum insulin levels and blood glucose (Figure 2B and S3A-D). Insulin resistance as measured by HOMA-IR was equivalent between WT and REDD1-KO mice (Figure 2C).

As expected, HFD-fed WT mice developed hepatomegaly (Figure 2D and S3E) and liver steatosis evidenced by histological analyses of the liver (Figure $2 \mathrm{~F}$ and S3F) and a 6.6-fold increase in their triglycerides content (Figure 2E-H). This is accompanied by hepatocyte injury demonstrated by the increase in circulating levels of 
AST and ALT (Figure 2I-J). Remarkably the hepatomegaly induced by the HFD was significantly reduced in HFD-fed REDD1-KO mice compared to the WT mice (Figure 2D and S3E), as well as liver steatosis (Figure 2E-H, S3F), and liver injury (Figure 2I-J).

Moreover, mRNA expression of Plin1, a lipid droplet protein, was also decreased in liver of HFD-fed REDD1KO mice compared to WT mice (Figure 2K). Altogether, these findings show that REDD1 deficiency protects HFD-fed mice against the development of hepatic steatosis and liver injury. This protection is not due to a change in obesity or insulin resistance development.

\section{Invalidation of REDD1 does not affect adipose tissue composition}

Since hepatic steatosis can result from a higher production of NEFA by dysfunctional adipose tissue and/or an increase in their uptake by the liver (40), we first investigated whether the reduced hepatic steatosis in HFD-fed REDD1-KO mice could be due to an improved lipid storage capacity of the adipose tissue and/or reduced NEFA flux. The weight of the epidydimal white adipose tissue (eWAT), the number of adipocytes per fat pad, and the adipocyte size were identical in WT and REDD1-KO mice fed with NCD. The eWAT of the two groups of mice expanded similarly on HFD with identical adipocyte size and number (Figure S4A-D).

HFD feeding increased the expression of REDD1 mRNA and protein in eWAT of WT mice (Figure S4E-F). Since adipose tissue inflammation contributes to its dysfunction, we measured the expression of different inflammatory markers in eWAT. The decrease in NLRP3 expression in the eWAT of HFD-fed REDD1-KO mice compared to WT may suggest a lower inflammatory state (Figure S4F). However, expression of several inflammatory genes was not modified between HFD-fed WT and REDD1-KO mice (Figure S4G).

Moreover, it was unlikely that the reduced hepatic steatosis of obese REDD1-KO mice was due to a reduction in NEFA flux from adipose tissue since circulating NEFA level was slightly but significantly increased in HFD-fed REDD1-KO mice compared to WT mice (Figure 3A). By contrast, no difference in circulating NEFA was observed between the two genotypes when mice were fed with NCD (Figure S5A).

We then investigated whether the uptake of NEFA or the export of lipid from the liver could be involved in the reduction of the hepatic steatosis by measuring expression of key genes involved in these processes. The expression of CD36 mRNA, which is implicated in the uptake of NEFA, and the expression of ApoB mRNA, involved in the export of triglycerides via the assembly and the secretion of VLDL, were not modified between 
HFD-fed WT and REDD1-KO mice (Figure 3B). Moreover, circulating triglycerides were not modified between WT and REDD1-KO fed with NCD or HFD (Figure S5B).

\section{REDD1 deficiency decreases lipogenic pathway in liver of obese mice}

We then investigated whether REDD1 deficiency may reduce hepatic de novo lipogenesis under HFD. We measured the mRNA expression of SREBP-1c, the main transcription factor regulating the expression of keys enzymes of lipogenesis including FASN (fatty acid synthase) and SCD1 (stearoyl-CoA desaturase 1). The expression of these three genes is lower in liver of REDD1-KO mice compared to WT mice (Figures 3B). The protein expression of FASN was also markedly reduced (Figure 3C). The decreased expression of SREBP-1c mRNA was not due to an increase in the expression of two SREBP-1c inhibitors, Insig2a and DEC1 $(41,42)$ (Figure 3D). Expression of genes involved in de novo lipogenesis was not modified in liver of NCD-fed REDD1-KO mice compared to WT mice (Figure S5C-E)

Since the AKT-mTORC1 axis regulates SREBP-1c expression and lipogenesis, we examined whether this pathway was different in liver of HFD-fed REDD1-KO mice compared to HFD-fed WT mice. The phosphorylation of AKT on threonine 308 and serine 473 residues was identical in the liver of HFD-fed REDD1-KO mice compared to WT mice (Figure 3E). By contrast, the phosphorylation of S6 and 4E-BP1, two downstream targets of mTORC1, was decreased in the liver of HFD-fed REDD1-KO mice compared to WT mice (Figure 3F). Thus, mTORC1 activity seems unexpectedly decreased in the liver of HFD-fed REDD1-KO mice and this may contribute to a decrease in lipogenesis.

We also evaluated the activation of mTORC1 signaling pathway in skeletal muscle of WT and REDD1-KO mice (Figure S6). The phosphorylation of S6 and 4EBP1 was increased in muscle of NCD-fed REDD1-KO mice compared to WT mice, whereas no activation was found in HFD-fed REDD1-KO mice.

\section{REDD1 deficiency induces autophagy and mitophagy signaling pathways in liver}

Healthy mitochondria are crucial for the adequate control of lipid metabolism in the liver. Moreover, failure to remove damaged mitochondria because of an attenuation of autophagy/mitophagy has been correlated with liver steatosis (43). 
Since mTORC1 regulates autophagy pathways, we evaluated the phosphorylation level of ULK on S757. ULK phosphorylation on S757 was decreased in liver of HFD-fed REDD1-KO mice. In parallel, protein expression of autophagy and/or mitophagy regulators such as beclin-1, LC3II, BNIP3L, and Parkin was increased whereas p62 expression was decreased in liver of HFD-fed REDD1-KO mice compared to WT mice (Figure 4A-B).

Electron microscopy analysis revealed an increase in the size of mitochondria in liver of HFD-fed WT mice compared to NCD-fed WT mice (Figure 4C-E). No such increase was observed in liver of HFD-fed REDD1$\mathrm{KO}$ and even in the liver of NCD-fed REDD1-KO mice, mitochondria size was smaller compared to WT mice (Figure 4C-E). These data suggest that the lack of REDD1 in liver of obese mice facilitates autophagy/mitophagy pathways preventing the accumulation of large mitochondria. To confirm our hypothesis, we evaluated the colocalization of mitochondria and lysosome in liver sections by immunofluorescence using AIF (mitochondria) and LAMP2 (lysosome) (Figure 4F-G, S7C). The percentage of mitochondria showing colocalization between AIF and LAMP2 was increased in liver of HFD-fed REDD1-KO mice compared to WT mice.

Since a decrease in fatty acid beta-oxidation contributes to the pathogenesis of fatty liver diseases, we examined whether this decrease in the size of mitochondria could be associated with an increase in the expression of genes involved in fatty acid beta-oxidation in the liver of HFD-fed REDD1-KO. The expression of PPAR $\alpha$ coactivator PGC1- $\alpha$ was increased in the liver of NCD-fed (Figure S7B) and HFD-fed REDD1-KO mice compared to WT mice (Figure 5A). Moreover, the expression of the protein Carnityl PalmitoylTransferase 1 (CPT1) responsible for the translocation of fatty acids from the cytosol to the mitochondrial matrix, the rate limiting step for the oxidation of long chain fatty acids (44), was increased in the liver of HFD-fed REDD1-KO mice compared to WT mice (Figure 5B). Finally, we measured the level of $\beta$-hydroxybutyrate which is produced in the liver from fatty acids via mitochondrial $\beta$-oxidation, in serum of mice after 16 hours of fasting. In figure $5 \mathrm{C}$, although it is just below the limit of statistical significance $(\mathrm{p}=0.06), \beta$-hydroxybutyrate was increased in HFD-fed REDD1-KO mice.

Altogether, our results suggest that REDD1 deficiency regulates mitophagy which could lead to an improvement of mitochondria fitness and oxidative capacity. 


\section{DISCUSSION}

In this study, we demonstrated that in vivo deficiency of REDD1 prevents the development of nonalcoholic hepatic steatosis.

REDD1 expression is increased in the adipose tissue and the liver of obese mice. Moreover, its expression is increased in the liver of obese patients and is correlated with the development and the severity of NAFLD. These observations suggest that REDD1 could be involved in the pathogenesis of liver disease. Implication of REDD1 in hepatic disease has been proposed since its expression is decreased in liver of morbidly obese women after weight loss (45). Our study shows that REDD1 expression is increased in adipose tissue and liver in obese conditions, and that REDD1 expression in liver correlates with the degree of steatosis and the insulin resistance state of obese patients. Previous studies have shown in skeletal muscle that REDD1 expression is increased in several models of obesity and/or diabetes such as ob/ob mice, diet-induced obesity, diabetes induced by injection of streptozotocin, and in muscle of type-2 diabetic patients after hyperinsulinemiceuglycemic clamp $(15,25,46,47)$. All these observations suggest that obesity leads to an increase of REDD1 in insulin-target tissues. Although the molecular mechanisms controlling the regulation of REDD1 expression during obesity remain unresolved, hypoxia, p53 activation or ER stress could be involved (10, 28, 48-51).

In NCD-fed mice, we did not detect any modifications of glucose tolerance between WT and REDD1-KO mice. WT and REDD1-KO mice had similar weight gain, glucose intolerance and insulin resistance under HFD. These observations are in contrast with two studies showing that loss of REDD1 promotes glucose and insulin intolerance in NCD conditions (26) and that REDD1-KO mice were resistant to the development of obesity after HFD (52). However, the transgenic mice used in these studies have a different genetic background (C57B1/6x129SvEv) compared to C57B16/J in the present study and it has been shown that genetic background impact glucose metabolism and the ability of mice to develop obesity $(53,54)$. Finally, it should be noted that in Williamson et al., WT and REDD1-KO mice have similar body weight at the end of the high fat diet (WT-HFD: 44.1g vs KO-HFD:46.4g) (52).

We have previously shown that downregulation of REDD1 in 3T3-L1 adipocytes decreases insulin signaling through mTORC1 activation (27). However, in the present manuscript, absence of REDD1 leads to the development of HFD-induced insulin resistance similar than in WT mice. These opposing effects of absence of REDD1 could be related to the transient vs prolonged inhibition of mTORC1. This dual effect of REDD1 has already been observed in other models. For instance, REDD1-KO mice are protected from lung emphysema 
induced by exposure to cigarette smoke. whereas treatment of WT mice with rapamycin protected WT mice against acute cigarette smoke induced inflammation (55).

Epidydimal adipose tissue analysis showed no differences in term of number and size of adipocytes. We have previously shown that loss of REDD1 prevented the development of inflammation in adipose tissue of LPStreated mice (21). Since obesity is characterized by a low grade systemic and adipose tissue inflammation, we would expect that adipose tissue inflammation would be reduced in HFD REDD1-KO mice. However, beside downregulation of NLRP3 expression in adipose tissue of REDD1-KO mice, the expression of other inflammation markers was not decreased, suggesting that invalidation of REDD1 can prevent LPS-induced inflammation but not the metabolic inflammation induced by obesity.

Importantly, even if REDD1-KO mice developed obesity in response to HFD, these mice are protected against obesity-induced hepatic steatosis and liver injury. A decrease in lipogenesis regulation in liver of HFD-fed REDD1-KO mice could be involved in this protection. Indeed, we found that the expression of lipogenic enzymes including SREBP-1c, FASN and SCD1 is decreased in liver of HFD-fed REDD1-KO mice.

REDD-1 is an inhibitor of mTORC1, and mTORC1 activity was increased in the liver of REDD1-KO and WT mice in NCD (Figure S5F) and decreased in HFD compared to WT mice. Similar observations were published with an increase of mTORC1 activity in REDD1-KO mice only in NCD (52). Although several publications showed that REDD1 expression inversely correlates with mTORC1 activity, it has also been shown that modulation of REDD1 expression does not always influence mTORC1 activity. For instance, disruption of REDD1 activity does not activate mTORC1 signaling pathway in hepatocytes (56), S6K phosphorylation is not increased in REDD1-KO mice compared to WT mice in muscle (26), and overexpression of REDD1 in C3H10T1/2 adipocytes does not decrease S6K phosphorylation (28). The mechanisms involved remain unknown, but we can also propose that the expression of other proteins, such as DEPTOR, implicated in mTORC1 inhibition could be increased to prevent upregulation of mTORC1 activity.

The implication of mTORC1 in the development of hepatic steatosis remains unclear since mice with raptordeficient liver are sensitive or resistant to steatosis $(57,58)$. Upregulation of mTORC1 after liver-specific invalidation of TSC1 (LTsc1KO) protects mice against diet-induced hepatic steatosis and is associated with a decrease in the induction of SREBP-1c and lipogenesis $(42,59,60)$. In LTsc1KO mice, mTORC1 dependent and independent mechanisms inhibits hepatic steatosis through Insig2a which controls SREBP1c-dependent lipogenesis (42). However, in REDD1-KO mice, Insig2a expression was not modified excluding its implication in the decreased expression of SREBP1c. FGF21 has been shown to be implicated in the protection against 
hepatic steatosis in Tsc1 KO model (61) but its expression was not modified between WT and REDD1-KO mice (data not shown).

Mitochondria could also be involved in the protection against steatosis. Under nutrients-rich conditions, mTORC1 inhibits autophagy processes through the phosphorylation of ULK1. The complex ULK1 which is composed of ULK1, Atg13, FIP2000 and Atg101 is implicated in autophagosome formation. Phosphorylation of ULK1 by mTORC1 on serine 757 , prevents its activation leading to the inhibition of autophagy $(62,63)$.

In HFD-fed REDD1-KO mice, phosphorylation of S757-ULK was decreased compared to WT mice suggesting that autophagy is enhanced in HFD-REDD1-KO livers. This is associated with an increased expression of beclin, expression of LC3-II and decreased p62 protein level in REDD1-KO mice which together suggest that autophagy flux is increased. Depolarized mitochondria are removed through the PINK1-Parkin system allowing the ubiquitination of mitochondria, recognition by p62 and their subsequent degradation. We found that Parkin expression was increased in REDD1-KO mice. This is correlated with a decrease of the size of mitochondria in the liver of REDD1-KO mice compared to WT mice. Moreover, the percentage of mitochondria showing colocalization between AIF (mitochondria) and LAMP2 (lysosome) was increased in liver HFD-fed REDD1KO mice. Enlarged and dysfunctional mitochondria are found in hepatocytes of NAFLD patients. It has been shown that loss of Opa1, which regulates fusion of mitochondria, decreases mitochondrial size leading to a rescue of liver damage in a mouse model of hepatic steatosis (64). Moreover, specific invalidation of Atg5 and Atg7 in hepatocytes increased intracellular lipids in vitro and in vivo (65). Altogether, these observations suggest that loss of REDD1 increases mitophagy to remove dysfunctional mitochondria allowing the presence of smaller but functional mitochondria.

Molecular mechanisms implicated in the regulation of mitophagy by REDD1 remains unclear. Britto and collaborators have shown that REDD1 associates with GRP75, a protein implicated in the formation of MAM (mitochondrial associated endoplasmic reticulum membranes) through interaction with IP3R in ER and mitochondrial VDAC $(24,66)$. Absence of REDD1 lead to an increase in the amount of MAM in human primary myoblasts and in skeletal muscle of mice treated with dexamethasone (24). After activation of mitophagy, PINK1 and beclin are localized at MAM where they promote the formation of autophagosomes (67). It is then tempting to suggest that REDD1, by modulating the amount of MAM through its association with GRP75, can also regulate the formation of autophagosome and mitophagy. However, the role of REDD1 in the regulation of mitophagy remains unclear. 
In MEF cells, Lafarge and collaborators showed that an increased respiration rate was observed in REDD1-KO MEF (29). A similar observation was made by Britto et al. who showed that mitochondrial respiration is increased in REDD1-KO in permeabilized myofibers supporting a higher mitophagy in REDD1-KO mice and that expression of markers of mitophagy is increased in REDD1 KO myofibers in response to exercise (24). By contrast, Qiao et al. showed that autophagy is impaired in response to hypoxia in absence of REDD1 and that loss of REDD1 suppressed autophagy through both mTORC1-dependent and independent mechanisms. They observed that the number and the size of mitochondria are increased in REDD1-KO cells. mTORC1independent autophagy involves redox-dependent regulation (20). Accordingly, REDD1 deletion impairs mitophagy in mice cartilage (68) and silencing REDD1 expression in bladder urothelial carcinoma cell lines decreased cell proliferation, increased apoptosis, and decreased autophagy (69). Electron microscopy of liver showed a decrease of glycogen (black granules) in HFD-fed REDD1-KO mice (Figure 4). Granules of glycogen are also degraded by autophagosomes through glycophagy. Although we did not quantify the amount of glycogen, Britto et al have found REDD1 deletion enhanced muscle glycogen depletion in response to exercise (24).

In addition, we found that serum content of $\beta$-hydroxybutyrate, as well as PGC1 $\alpha$ and CPT-1 expression were increased in the liver of HFD-fed REDD1-KO mice. PGC1 $\alpha$ is a transcriptional coactivator that regulates mitochondrial biogenesis and fatty acid oxidation. PGC1 $\alpha$ interacts with PPAR $\alpha$ transcription factor to regulate fatty acid $\beta$-oxidation pathways and liver specific invalidation of PPAR $\alpha$ promotes hepatic steatosis (70).

REDD1-KO mice are protected against hepatic steatosis but still develop an obesity associated with glucose intolerance and insulin resistance suggesting that hepatic steatosis can be disconnected from insulin resistance. This has been observed in other models. For instance, mice overexpressing ChREBP fed with HFD have improved insulin signaling despite worst hepatic steatosis (71). On the other hand, p110 $\alpha-/-$ mice are resistant to the development of hepatic steatosis but displays glucose intolerance and loss of AKT2 in $o b / o b$ mice decrease liver steatosis without improvement of hyperglycemia $(72,73)$. One possible explanation is that circulating NEFA remains elevated in REDD1-KO mice compared to WT mice and could induce deleterious effects on insulin sensitivity and metabolism regulation in other tissue such as muscles.

In conclusion, we demonstrate that REDD1 plays a role in the development of obesity-induced metabolic complications and that loss of REDD1 decreases lipogenesis pathways, promotes hepatic mitophagy and prevents the development of nonalcoholic hepatic steatosis. 
Acknowledgements: The authors acknowledge Quark Pharmaceuticals for providing the REDD1-knockout mice. The authors gratefully acknowledge Veronique Corcelle and the $\mathrm{C} 3 \mathrm{M}$ animal facility team for their valuable assistance with animal care. The help of Maeva Gesson and Marie Irondelle is acknowledged. We sincerely thank the GIS-IBISA multi-sites platform Microscopie Imagerie Côte d'Azur (MICA), and particularly the imaging site of C3M (INSERM U1065) supported by Conseil Régional, Conseil Départemental, and IBISA. We thank Nathalie Mazure and Guillaume Robert for technical help.

This work was supported by grants from INSERM (France), the French Government (National Research Agency, ANR): \#ANR-15-CE14-0016-01, \#ANR-18-CE14-0019-02 and through the "Investments for the Future" LABEX SIGNALIFE (\#ANR-11-LABX-0028-01) and the UCAJEDI Investments in the Future project (\#ANR-15-IDEX-01), Société Francophone du Diabète SFD/Abbott, Université Côte d'Azur, Région Provence-Alpes-Cote-d'Azur, Conseil Général des Alpes Maritimes and . CCMA electron microscopy equipment have been funded by the Région Sud-Provence-Alpes-Côte-d'Azur, the Conseil Général des Alpes Maritimes, the GIS-IBiSA and Cancéropôle Provence-Alpes-Côte d'Azur.

\section{Author contributions}

K. Dumas and S. Giorgetti-Peraldi designed research; K. Dumas, C. Ayachi, J. Gilleron, S. Lacas-Gervais, F. Pastor, P. Peraldi, N. Vaillant, S. Bonnafous, S. Patouraux, S. Giorgetti-Peraldi performed research; R. Anty, A. Tran participated in human sample and data collection; K. Dumas, C. Ayachi, J. Gilleron, F.B. Favier, P. Peraldi, L. Yvan-Charvet, P. Gual, M. Cormont, JF. Tanti, S. Giorgetti-Peraldi analyzed data; M. Cormont, JF. Tanti and S. Giorgetti-Peraldi wrote the paper 


\section{Legend of figures}

Figure 1: Expression of REDD1 is increased in liver in obese mice and human patients

(A) C57B16/J mice were subjected to normal chow diet (NCD) or high fat diet (HFD) for 25 weeks. Liver tissue

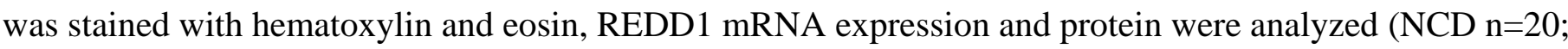
HFD n=22) (B) Liver biopsies from morbidly obese patients were stained with hematoxylin and eosin. REDD1 mRNA expression was analyzed in the liver of obese patients without $(n=5)$ or with steatosis $(n=15)$. (C) Correlations between REDD1 expression and percent of steatosis and between REDD1 and HOMA-IR were analyzed using Spearman's rank correlation test.

\section{Figure 2: Loss of REDD1 prevents the development of hepatic steatosis}

(A) Body weight of WT and REDD1-KO mice after 25 weeks of normal chow diet (NCD) or high fat diet (HFD) ( $\mathrm{n}=10)$. (B) IP-GTT in NCD- and HFD-fed mice fasted for $16 \mathrm{~h}$ after 16 weeks of diet $(\mathrm{n}=24$ mice/group). (C) HOMA-IR index (Fasting glucose mmol/l x fasting insulin $\mu \mathrm{U} / \mathrm{ml} / 22.5$ ) after 16 weeks of diet ( $\mathrm{n}=10$ mice/group). (D) Liver weight in WT and REDD1-KO mice fed with NCD and HFD for 25 weeks ( $\mathrm{n}=20-23$ mice/group). (E) Hepatic triglyceride contents ( $\mathrm{n}=10$ mice/group). (F) Quantification of hepatic steatosis ( $\mathrm{n}=10$ mice/group) from $\mathrm{H} \& \mathrm{E}$ staining of liver tissue. (G) Liver tissues were analyzed by Oil-Red $\mathrm{O}$ staining or (H) H\&E staining. Representative images are shown. (I) Plasma levels of ALT and (J) AST were evaluated after 23 weeks of diet (n=9-10/group). (K) Plin1 mRNA expression (relative expression compared to WT-HFD).

\section{Figure 3: REDD1 deficiency decreases hepatic de novo lipogenesis}

(A) Circulating NEFA levels of WT and REDD1-KO mice after 14 weeks of HFD ( $\mathrm{n}=10$ mice/group). (B) mRNA level in liver of WT and REDD1-KO mice after 25 weeks of HFD ( $\mathrm{n}=10$ mice/group, relative expression compared to WT-HFD). (C) Immunoblot of FASN in liver of HFD-fed WT and REDD1-KO mice. Quantification of relative expression (using ERK2 as loading control) (WT n=8 mice/group, KO $\mathrm{n}=10$ mice/group). Representative blot is shown (each lane represents one mice). (D) mRNA level in liver of WT 
and REDD1-KO mice after 25 weeks of HFD ( $\mathrm{n}=10$ mice/group, relative expression compared to WT-HFD). (E-F) Immunoblots in liver of HFD-fed WT and REDD1-KO mice. Quantification of phosphorylation level (ratio phosphorylated/total protein) (WT n=8 mice/group, KO n=10 mice/group). Representative blot is shown (each lane represents one mice).

\section{Figure 4: Autophagy signaling pathways are increased in livers of REDD1-KO mice}

(A) Immunoblots using indicated antibodies in liver from HFD-fed WT and REDD1-KO mice (each lane represents one mice). (B) Quantification of relative expression (using HSP90 as loading control) (WT n=6, KO $\mathrm{n}=8$ mice/group). (C) Representative pictures of electron microscopy of liver tissue from NCD- and HFD-fed WT and REDD1-KO mice (LD=lipid droplet; *=mitochondria). (D) quantification of mitochondrial area in liver of mice (number of mitochondria measured in WT-NCD: 552, KO-NCD: 507, WT-HFD: 140, KO-HFD 217). (E) Distribution analysis of mitochondrial area. (F) Representative images of confocal microscopy of liver sections using antibodies to AIF and LAMP2. (G) Quantification of mitochondria showing colocalization between AIF and LAMP2.

Figure 5: REDD1 deficiency increases $\beta$-oxidation markers

(A) mRNA level in liver of HFD-fed WT and REDD1-KO (relative expression compared to WT-HFD) (B) Immunoblots using indicated antibodies in livers from HFD-fed WT and REDD1-KO mice. Representative blot is shown (each lane represents one mice). Quantification of relative expression (using HSP90 as loading control) WT n=6, KO n=8 mice/group). (C) serum b-hydroxybutyrate ( 8 mice per group). 


\section{References}

1. Rinella, M. E. (2015) Nonalcoholic fatty liver disease: a systematic review. JAMA 313, 2263-2273

2. Scheen, A. J., and Luyckx, F. H. (2002) Obesity and liver disease. Best Pract Res Clin Endocrinol Metab 16, 703-716

3. Younossi, Z. M., Koenig, A. B., Abdelatif, D., Fazel, Y., Henry, L., and Wymer, M. (2016) Global epidemiology of nonalcoholic fatty liver disease-Meta-analytic assessment of prevalence, incidence, and outcomes. Hepatology 64, 73-84

4. Hu, M., Phan, F., Bourron, O., Ferre, P., and Foufelle, F. (2017) Steatosis and NASH in type 2 diabetes. Biochimie 143, 37-41

5. Nassir, F., Rector, R. S., Hammoud, G. M., and Ibdah, J. A. (2015) Pathogenesis and Prevention of Hepatic Steatosis. Gastroenterol Hepatol (N Y) 11, 167-175

6. Nassir, F., and Ibdah, J. A. (2014) Role of mitochondria in nonalcoholic fatty liver disease. Int J Mol Sci 15, 8713-8742

7. Wakabayashi, T. (2002) Megamitochondria formation - physiology and pathology. J Cell Mol Med 6, 497-538

8. Neuman, M. G., French, S. W., French, B. A., Seitz, H. K., Cohen, L. B., Mueller, S., Osna, N. A., Kharbanda, K. K., Seth, D., Bautista, A., Thompson, K. J., McKillop, I. H., Kirpich, I. A., McClain, C. J., Bataller, R., Nanau, R. M., Voiculescu, M., Opris, M., Shen, H., Tillman, B., Li, J., Liu, H., Thomes, P. G., Ganesan, M., and Malnick, S. (2014) Alcoholic and non-alcoholic steatohepatitis. Exp Mol Pathol 97, 492-510

9. Arab, J. P., Arrese, M., and Trauner, M. (2018) Recent Insights into the Pathogenesis of Nonalcoholic Fatty Liver Disease. Annu Rev Pathol 13, 321-350

10. Ellisen, L. W., Ramsayer, K. D., Johannessen, C. M., Yang, A., Beppu, H., Minda, K., Oliner, J. D., McKeon, F., and Haber, D. A. (2002) REDD1, a developmentally regulated transcriptional target of p63 and p53, links p63 to regulation of reactive oxygen species. Mol Cell 10, 995-1005

11. Shoshani, T., Faerman, A., Mett, I., Zelin, E., Tenne, T., Gorodin, S., Moshel, Y., Elbaz, S., Budanov, A., Chajut, A., Kalinski, H., Kamer, I., Rozen, A., Mor, O., Keshet, E., Leshkowitz, D., Einat, P., Skaliter, R., and Feinstein, E. (2002) Identification of a novel hypoxia-inducible factor 1-responsive gene, RTP801, involved in apoptosis. Mol Cell Biol 22, 2283-2293

12. Cho, S. S., Kim, K. M., Yang, J. H., Kim, J. Y., Park, S. J., Kim, S. J., Kim, J. K., Cho, I. J., and Ki, S. H. (2018) Induction of REDD1 via AP-1 prevents oxidative stress-mediated injury in hepatocytes. Free Radic Biol Med 124, 221-231

13. Whitney, M. L., Jefferson, L. S., and Kimball, S. R. (2009) ATF4 is necessary and sufficient for ER stress-induced upregulation of REDD1 expression. Biochem Biophys Res Commun 379, 451-455

14. Regazzetti, C., Bost, F., Le Marchand-Brustel, Y., Tanti, J. F., and Giorgetti-Peraldi, S. (2010) Insulin induces REDD1 expression through hypoxia-inducible factor 1 activation in adipocytes. $J$ Biol Chem 285, 5157-5164

15. Williamson, D. L., Dungan, C. M., Mahmoud, A. M., Mey, J. T., Blackburn, B. K., and Haus, J. M. (2015) Aberrant REDD1-mTORC1 responses to insulin in skeletal muscle from Type 2 diabetics. Am J Physiol Regul Integr Comp Physiol 309, R855-863

16. Dennis, M. D., Kimball, S. R., Fort, P. E., and Jefferson, L. S. (2015) Regulated in development and DNA damage 1 is necessary for hyperglycemia-induced vascular endothelial growth factor expression in the retina of diabetic rodents. J Biol Chem 290, 3865-3874 
17. Wang, H., Kubica, N., Ellisen, L. W., Jefferson, L. S., and Kimball, S. R. (2006) Dexamethasone represses signaling through the mammalian target of rapamycin in muscle cells by enhancing expression of REDD1. J Biol Chem 281, 39128-39134

18. Dennis, M. D., Coleman, C. S., Berg, A., Jefferson, L. S., and Kimball, S. R. (2014) REDD1 enhances protein phosphatase 2A-mediated dephosphorylation of Akt to repress mTORC1 signaling. Sci Signal 7, ra68

19. DeYoung, M. P., Horak, P., Sofer, A., Sgroi, D., and Ellisen, L. W. (2008) Hypoxia regulates TSC1/2mTOR signaling and tumor suppression through REDD1-mediated 14-3-3 shuttling. Genes Dev 22, 239-251

20. Qiao, S., Dennis, M., Song, X., Vadysirisack, D. D., Salunke, D., Nash, Z., Yang, Z., Liesa, M., Yoshioka, J., Matsuzawa, S., Shirihai, O. S., Lee, R. T., Reed, J. C., and Ellisen, L. W. (2015) A REDD1/TXNIP pro-oxidant complex regulates ATG4B activity to control stress-induced autophagy and sustain exercise capacity. Nat Commun 6, 7014

21. Pastor, F., Dumas, K., Barthelemy, M. A., Regazzetti, C., Druelle, N., Peraldi, P., Cormont, M., Tanti, J. F., and Giorgetti-Peraldi, S. (2017) Implication of REDD1 in the activation of inflammatory pathways. Sci Rep 7, 7023

22. Xu, M. C., Shi, H. M., Wang, H., and Gao, X. F. (2013) Salidroside protects against hydrogen peroxideinduced injury in HUVECs via the regulation of REDD1 and mTOR activation. Mol Med Rep 8, 147153

23. Horak, P., Crawford, A. R., Vadysirisack, D. D., Nash, Z. M., DeYoung, M. P., Sgroi, D., and Ellisen, L. W. (2010) Negative feedback control of HIF-1 through REDD1-regulated ROS suppresses tumorigenesis. Proc Natl Acad Sci U S A 107, 4675-4680

24. Britto, F. A., Cortade, F., Belloum, Y., Blaquiere, M., Gallot, Y. S., Docquier, A., Pagano, A. F., Jublanc, E., Bendridi, N., Koechlin-Ramonatxo, C., Chabi, B., Francaux, M., Casas, F., Freyssenet, D., Rieusset, J., Giorgetti-Peraldi, S., Carnac, G., Ollendorff, V., and Favier, F. B. (2018) Glucocorticoiddependent REDD1 expression reduces muscle metabolism to enable adaptation under energetic stress. BMC Biol 16, 65

25. Lipina, C., and Hundal, H. S. (2016) Is REDD1 a Metabolic Eminence Grise? Trends Endocrinol Metab 27, 868-880

26. Dungan, C. M., Wright, D. C., and Williamson, D. L. (2014) Lack of REDD1 reduces whole body glucose and insulin tolerance, and impairs skeletal muscle insulin signaling. Biochem Biophys Res Commun 453, 778-783

27. Regazzetti, C., Dumas, K., Le Marchand-Brustel, Y., Peraldi, P., Tanti, J. F., and Giorgetti-Peraldi, S. (2012) Regulated in Development and DNA Damage Responses -1 (REDD1) Protein Contributes to Insulin Signaling Pathway in Adipocytes. PLoS One 7, e52154

28. Schupp, M., Chen, F., Briggs, E. R., Rao, S., Pelzmann, H. J., Pessentheiner, A. R., Bogner-Strauss, J. G., Lazar, M. A., Baldwin, D., and Prokesch, A. (2013) Metabolite and transcriptome analysis during fasting suggest a role for the p53-Ddit4 axis in major metabolic tissues. BMC Genomics 14, 758

29. Lafarge, J. C., Pini, M., Pelloux, V., Orasanu, G., Hartmann, G., Venteclef, N., Sulpice, T., Shi, G. P., Clement, K., and Guerre-Millo, M. (2014) Cathepsin S inhibition lowers blood glucose levels in mice. Diabetologia 57, 1674-1683

30. Lebeaupin, C., Vallee, D., Hazari, Y., Hetz, C., Chevet, E., and Bailly-Maitre, B. (2018) Endoplasmic reticulum stress signalling and the pathogenesis of non-alcoholic fatty liver disease. J Hepatol 69, 927 947

31. Patouraux, S., Rousseau, D., Bonnafous, S., Lebeaupin, C., Luci, C., Canivet, C. M., Schneck, A. S., Bertola, A., Saint-Paul, M. C., Iannelli, A., Gugenheim, J., Anty, R., Tran, A., Bailly-Maitre, B., and Gual, P. (2017) CD44 is a key player in non-alcoholic steatohepatitis. J Hepatol 67, 328-338 
32. Schindelin, J., Arganda-Carreras, I., Frise, E., Kaynig, V., Longair, M., Pietzsch, T., Preibisch, S., Rueden, C., Saalfeld, S., Schmid, B., Tinevez, J. Y., White, D. J., Hartenstein, V., Eliceiri, K., Tomancak, P., and Cardona, A. (2012) Fiji: an open-source platform for biological-image analysis. Nat Methods 9, 676-682

33. Bekri, S., Gual, P., Anty, R., Luciani, N., Dahman, M., Ramesh, B., Iannelli, A., Staccini-Myx, A., Casanova, D., Ben Amor, I., Saint-Paul, M. C., Huet, P. M., Sadoul, J. L., Gugenheim, J., Srai, S. K., Tran, A., and Le Marchand-Brustel, Y. (2006) Increased adipose tissue expression of hepcidin in severe obesity is independent from diabetes and NASH. Gastroenterology 131, 788-796

34. Anty, R., Bekri, S., Luciani, N., Saint-Paul, M. C., Dahman, M., Iannelli, A., Amor, I. B., Staccini-Myx, A., Huet, P. M., Gugenheim, J., Sadoul, J. L., Le Marchand-Brustel, Y., Tran, A., and Gual, P. (2006) The inflammatory C-reactive protein is increased in both liver and adipose tissue in severely obese patients independently from metabolic syndrome, Type 2 diabetes, and NASH. Am J Gastroenterol 101, 1824-1833

35. Bertola, A., Ciucci, T., Rousseau, D., Bourlier, V., Duffaut, C., Bonnafous, S., Blin-Wakkach, C., Anty, R., Iannelli, A., Gugenheim, J., Tran, A., Bouloumie, A., Gual, P., and Wakkach, A. (2012) Identification of adipose tissue dendritic cells correlated with obesity-associated insulin-resistance and inducing Th17 responses in mice and patients. Diabetes 61, 2238-2247

36. Wallace, T. M., Levy, J. C., and Matthews, D. R. (2004) Use and abuse of HOMA modeling. Diabetes Care 27, 1487-1495

37. Kleiner, D. E., Brunt, E. M., Van Natta, M., Behling, C., Contos, M. J., Cummings, O. W., Ferrell, L. D., Liu, Y. C., Torbenson, M. S., Unalp-Arida, A., Yeh, M., McCullough, A. J., and Sanyal, A. J. (2005) Design and validation of a histological scoring system for nonalcoholic fatty liver disease. Hepatology 41, 1313-1321

38. Patouraux, S., Rousseau, D., Rubio, A., Bonnafous, S., Lavallard, V. J., Lauron, J., Saint-Paul, M. C., Bailly-Maitre, B., Tran, A., Crenesse, D., and Gual, P. (2014) Osteopontin deficiency aggravates hepatic injury induced by ischemia-reperfusion in mice. Cell Death Dis 5, e1208

39. Patouraux, S., Bonnafous, S., Voican, C. S., Anty, R., Saint-Paul, M. C., Rosenthal-Allieri, M. A., Agostini, H., Njike, M., Barri-Ova, N., Naveau, S., Le Marchand-Brustel, Y., Veillon, P., Cales, P., Perlemuter, G., Tran, A., and Gual, P. (2012) The osteopontin level in liver, adipose tissue and serum is correlated with fibrosis in patients with alcoholic liver disease. Plos One 7, e35612

40. Postic, C., and Girard, J. (2008) Contribution of de novo fatty acid synthesis to hepatic steatosis and insulin resistance: lessons from genetically engineered mice. J Clin Invest 118, 829-838

41. Choi, S. M., Cho, H. J., Cho, H., Kim, K. H., Kim, J. B., and Park, H. (2008) Stra13/DEC1 and DEC2 inhibit sterol regulatory element binding protein-1c in a hypoxia-inducible factor-dependent mechanism. Nucleic Acids Res 36, 6372-6385

42. Yecies, J. L., Zhang, H. H., Menon, S., Liu, S., Yecies, D., Lipovsky, A. I., Gorgun, C., Kwiatkowski, D. J., Hotamisligil, G. S., Lee, C. H., and Manning, B. D. (2011) Akt stimulates hepatic SREBP1c and lipogenesis through parallel mTORC1-dependent and independent pathways. Cell Metab 14, 21-32

43. Schuster, S., Cabrera, D., Arrese, M., and Feldstein, A. E. (2018) Triggering and resolution of inflammation in NASH. Nat Rev Gastroenterol Hepatol 15, 349-364

44. McGarry, J. D. (1995) The mitochondrial carnitine palmitoyltransferase system: its broadening role in fuel homoeostasis and new insights into its molecular features. Biochem Soc Trans 23, 321-324

45. Elam, M. B., Cowan, G. S., Jr., Rooney, R. J., Hiler, M. L., Yellaturu, C. R., Deng, X., Howell, G. E., Park, E. A., Gerling, I. C., Patel, D., Corton, J. C., Cagen, L. M., Wilcox, H. G., Gandhi, M., Bahr, M. H., Allan, M. C., Wodi, L. A., Cook, G. A., Hughes, T. A., and Raghow, R. (2009) Hepatic Gene Expression in Morbidly Obese Women: Implications for Disease Susceptibility. Obesity (Silver Spring) 
46. Gordon, B. S., Steiner, J. L., Williamson, D. L., Lang, C. H., and Kimball, S. R. (2016) Emerging role for regulated in development and DNA damage 1 (REDD1) in the regulation of skeletal muscle metabolism. Am J Physiol Endocrinol Metab 311, E157-174

47. Hulmi, J. J., Silvennoinen, M., Lehti, M., Kivela, R., and Kainulainen, H. (2012) Altered REDD1, myostatin, and Akt/mTOR/FoxO/MAPK signaling in streptozotocin-induced diabetic muscle atrophy. Am J Physiol Endocrinol Metab 302, E307-315

48. Vadysirisack, D. D., Baenke, F., Ory, B., Lei, K., and Ellisen, L. W. (2011) Feedback control of p53 translation by REDD1 and mTORC1 limits the p53-dependent DNA damage response. Mol Cell Biol 31, 4356-4365

49. Ben Sahra, I., Regazzetti, C., Robert, G., Laurent, K., Le Marchand-Brustel, Y., Auberger, P., Tanti, J. F., Giorgetti-Peraldi, S., and Bost, F. (2011) Metformin, independent of AMPK, induces mTOR inhibition and cell-cycle arrest through REDD1. Cancer Res 71, 4366-4372

50. Kimball, S. R., and Jefferson, L. S. (2012) Induction of REDD1 gene expression in the liver in response to endoplasmic reticulum stress is mediated through a PERK, eIF2alpha phosphorylation, ATF4dependent cascade. Biochem Biophys Res Commun 427, 485-489

51. Jin, H. O., Seo, S. K., Woo, S. H., Kim, E. S., Lee, H. C., Yoo, D. H., An, S., Choe, T. B., Lee, S. J., Hong, S. I., Rhee, C. H., Kim, J. I., and Park, I. C. (2009) Activating transcription factor 4 and CCAAT/enhancer-binding protein-beta negatively regulate the mammalian target of rapamycin via Redd1 expression in response to oxidative and endoplasmic reticulum stress. Free Radic Biol Med 46, $1158-1167$

52. Williamson, D. L., Li, Z., Tuder, R. M., Feinstein, E., Kimball, S. R., and Dungan, C. M. (2014) Altered nutrient response of mTORC1 as a result of changes in REDD1 expression: effect of obesity vs. REDD1 deficiency. J Appl Physiol (1985) 117, 246-256

53. Kleinert, M., Clemmensen, C., Hofmann, S. M., Moore, M. C., Renner, S., Woods, S. C., Huypens, P., Beckers, J., de Angelis, M. H., Schurmann, A., Bakhti, M., Klingenspor, M., Heiman, M., Cherrington, A. D., Ristow, M., Lickert, H., Wolf, E., Havel, P. J., Muller, T. D., and Tschop, M. H. (2018) Animal models of obesity and diabetes mellitus. Nat Rev Endocrinol 14, 140-162

54. Almind, K., and Kahn, C. R. (2004) Genetic determinants of energy expenditure and insulin resistance in diet-induced obesity in mice. Diabetes 53, 3274-3285

55. Yoshida, T., Mett, I., Bhunia, A. K., Bowman, J., Perez, M., Zhang, L., Gandjeva, A., Zhen, L., Chukwueke, U., Mao, T., Richter, A., Brown, E., Ashush, H., Notkin, N., Gelfand, A., Thimmulappa, R. K., Rangasamy, T., Sussan, T., Cosgrove, G., Mouded, M., Shapiro, S. D., Petrache, I., Biswal, S., Feinstein, E., and Tuder, R. M. (2010) Rtp801, a suppressor of mTOR signaling, is an essential mediator of cigarette smoke-induced pulmonary injury and emphysema. Nat Med 16, 767-773

56. Wolff, N. C., Vega-Rubin-de-Celis, S., Xie, X. J., Castrillon, D. H., Kabbani, W., and Brugarolas, J. (2011) Cell-type-dependent regulation of mTORC1 by REDD1 and the tumor suppressors TSC1/TSC2 and LKB1 in response to hypoxia. Mol Cell Biol 31, 1870-1884

57. Peterson, T. R., Sengupta, S. S., Harris, T. E., Carmack, A. E., Kang, S. A., Balderas, E., Guertin, D. A., Madden, K. L., Carpenter, A. E., Finck, B. N., and Sabatini, D. M. (2011) mTOR complex 1 regulates lipin 1 localization to control the SREBP pathway. Cell 146, 408-420

58. Umemura, A., Park, E. J., Taniguchi, K., Lee, J. H., Shalapour, S., Valasek, M. A., Aghajan, M., Nakagawa, H., Seki, E., Hall, M. N., and Karin, M. (2014) Liver damage, inflammation, and enhanced tumorigenesis after persistent mTORC1 inhibition. Cell Metab 20, 133-144

59. Kenerson, H. L., Yeh, M. M., and Yeung, R. S. (2011) Tuberous sclerosis complex-1 deficiency attenuates diet-induced hepatic lipid accumulation. Plos One 6, e18075

60. Kenerson, H. L., Subramanian, S., McIntyre, R., Kazami, M., and Yeung, R. S. (2015) Livers with constitutive mTORC1 activity resist steatosis independent of feedback suppression of Akt. Plos One 10, $\mathrm{e} 0117000$ 
61. Cornu, M., Oppliger, W., Albert, V., Robitaille, A. M., Trapani, F., Quagliata, L., Fuhrer, T., Sauer, U., Terracciano, L., and Hall, M. N. (2014) Hepatic mTORC1 controls locomotor activity, body temperature, and lipid metabolism through FGF21. Proc Natl Acad Sci U S A 111, 11592-11599

62. Saxton, R. A., and Sabatini, D. M. (2017) mTOR Signaling in Growth, Metabolism, and Disease. Cell 169, 361-371

63. Rabanal-Ruiz, Y., Otten, E. G., and Korolchuk, V. I. (2017) mTORC1 as the main gateway to autophagy. Essays Biochem 61, 565-584

64. Yamada, T., Murata, D., Adachi, Y., Itoh, K., Kameoka, S., Igarashi, A., Kato, T., Araki, Y., Huganir, R. L., Dawson, T. M., Yanagawa, T., Okamoto, K., Iijima, M., and Sesaki, H. (2018) Mitochondrial Stasis Reveals p62-Mediated Ubiquitination in Parkin-Independent Mitophagy and Mitigates Nonalcoholic Fatty Liver Disease. Cell Metab 28, 588-604 e585

65. Singh, R., Kaushik, S., Wang, Y., Xiang, Y., Novak, I., Komatsu, M., Tanaka, K., Cuervo, A. M., and Czaja, M. J. (2009) Autophagy regulates lipid metabolism. Nature 458, 1131-1135

66. Rieusset, J. (2017) Endoplasmic reticulum-mitochondria calcium signaling in hepatic metabolic diseases. Biochim Biophys Acta 1864, 865-876

67. Gelmetti, V., De Rosa, P., Torosantucci, L., Marini, E. S., Romagnoli, A., Di Rienzo, M., Arena, G., Vignone, D., Fimia, G. M., and Valente, E. M. (2017) PINK1 and BECN1 relocalize at mitochondriaassociated membranes during mitophagy and promote ER-mitochondria tethering and autophagosome formation. Autophagy 13, 654-669

68. Alvarez-Garcia, O., Matsuzaki, T., Olmer, M., Plate, L., Kelly, J. W., and Lotz, M. K. (2017) Regulated in Development and DNA Damage Response 1 Deficiency Impairs Autophagy and Mitochondrial Biogenesis in Articular Cartilage and Increases the Severity of Experimental Osteoarthritis. Arthritis Rheumatol 69, 1418-1428

69. Zeng, Q., Liu, J., Cao, P., Li, J., Liu, X., Fan, X., Liu, L., Cheng, Y., Xiong, W., Li, J., Bo, H., Zhu, Y., Yang, F., Hu, J., Zhou, M., Zhou, Y., Zou, Q., Zhou, J., and Cao, K. (2018) Inhibition of REDD1 Sensitizes Bladder Urothelial Carcinoma to Paclitaxel by Inhibiting Autophagy. Clin Cancer Res 24, 445-459

70. Montagner, A., Polizzi, A., Fouche, E., Ducheix, S., Lippi, Y., Lasserre, F., Barquissau, V., Regnier, M., Lukowicz, C., Benhamed, F., Iroz, A., Bertrand-Michel, J., Al Saati, T., Cano, P., Mselli-Lakhal, L., Mithieux, G., Rajas, F., Lagarrigue, S., Pineau, T., Loiseau, N., Postic, C., Langin, D., Wahli, W., and Guillou, H. (2016) Liver PPARalpha is crucial for whole-body fatty acid homeostasis and is protective against NAFLD. Gut 65, 1202-1214

71. Benhamed, F., Denechaud, P. D., Lemoine, M., Robichon, C., Moldes, M., Bertrand-Michel, J., Ratziu, V., Serfaty, L., Housset, C., Capeau, J., Girard, J., Guillou, H., and Postic, C. (2012) The lipogenic transcription factor ChREBP dissociates hepatic steatosis from insulin resistance in mice and humans. $J$ Clin Invest 122, 2176-2194

72. Chattopadhyay, M., Selinger, E. S., Ballou, L. M., and Lin, R. Z. (2011) Ablation of PI3K p110-alpha prevents high-fat diet-induced liver steatosis. Diabetes 60, 1483-1492

73. Leavens, K. F., Easton, R. M., Shulman, G. I., Previs, S. F., and Birnbaum, M. J. (2009) Akt2 is required for hepatic lipid accumulation in models of insulin resistance. Cell Metab 10, 405-418 
Table 1. Characteristics of 20 morbidly obese patients

\begin{tabular}{|c|c|c|c|c|c|}
\hline & withou & NAFLD & with $\mathrm{N}$ & FL & $\mathbf{p}$ \\
\hline $\mathrm{n}$ & 5 & & 15 & & \\
\hline Age (years) & 37.2 & \pm 7.0 & 37.2 & \pm 2.4 & 0.965 \\
\hline $\operatorname{Sex}(\mathrm{F} / \mathrm{M})$ & $4 / 1$ & & $12 / 3$ & & \\
\hline $\mathrm{BMI}\left(\mathrm{kg} / \mathrm{m}^{2}\right)$ & 43.3 & \pm 0.4 & 43.0 & \pm 1.1 & 0.727 \\
\hline ALT (IU/L) & 13.80 & \pm 1.66 & 31.27 & \pm 2.85 & 0.001 \\
\hline Insulin level (mIU/L) & 7.60 & \pm 0.81 & 16.54 & \pm 3.22 & 0.105 \\
\hline Glucose level (mmol/L) & 5.01 & \pm 0.07 & 5.42 & \pm 0.13 & 0.018 \\
\hline HOMA-IR & 1.68 & \pm 0.16 & 4.03 & \pm 0.81 & 0.047 \\
\hline $\mathrm{HbA} 1 \mathrm{c}(\%)$ & 5.22 & \pm 0.16 & 5.64 & \pm 0.12 & 0.116 \\
\hline Triglycerides (mmol/L) & 0.99 & \pm 0.17 & 1.72 & \pm 0.26 & 0.081 \\
\hline HDL cholesterol (mmol/L) & 1.39 & \pm 0.14 & 1.38 & \pm 0.09 & 1 \\
\hline NAFLD Activity Score (n) & $0(5)$ & & $1(0) / 2$ & $/ 3(9)$ & \\
\hline Grade of steatosis (n) & $0(5)$ & & $1(0) / 2$ & $/ 3(9)$ & \\
\hline Lobular inflammation (n) & $0(5)$ & & $0(15)$ & & \\
\hline Hepatocellular ballooning (n) & $0(5)$ & & $0(15)$ & & \\
\hline
\end{tabular}

Without NAFLD: patients with normal liver histology; With NAFL: patients with steatosis. Data are expressed as mean \pm SEM and compared using the Mann Whitney test for quantitative values and or Khi-deux test for qualitative values 

A. Mice
B. Morbidly obese patients

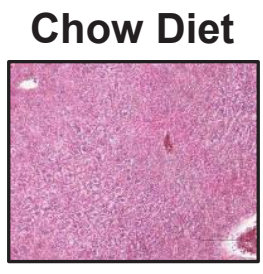

High Fat Diet
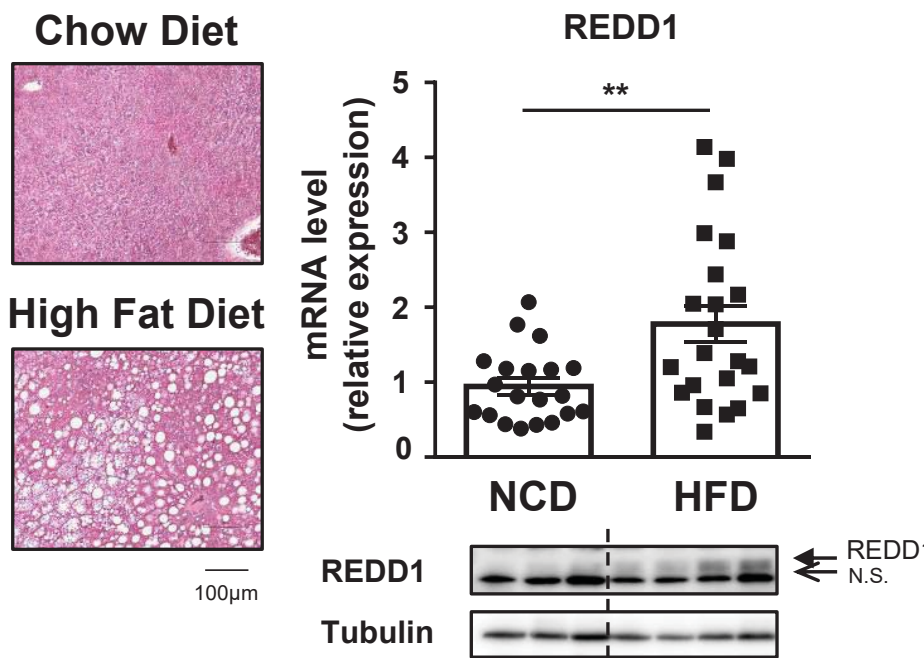

Without NAFLD

REDD1
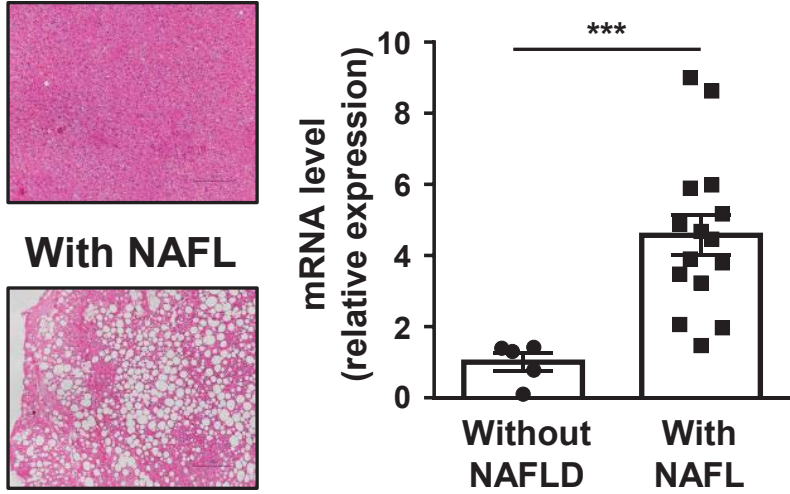

C. Morbidly obese patients
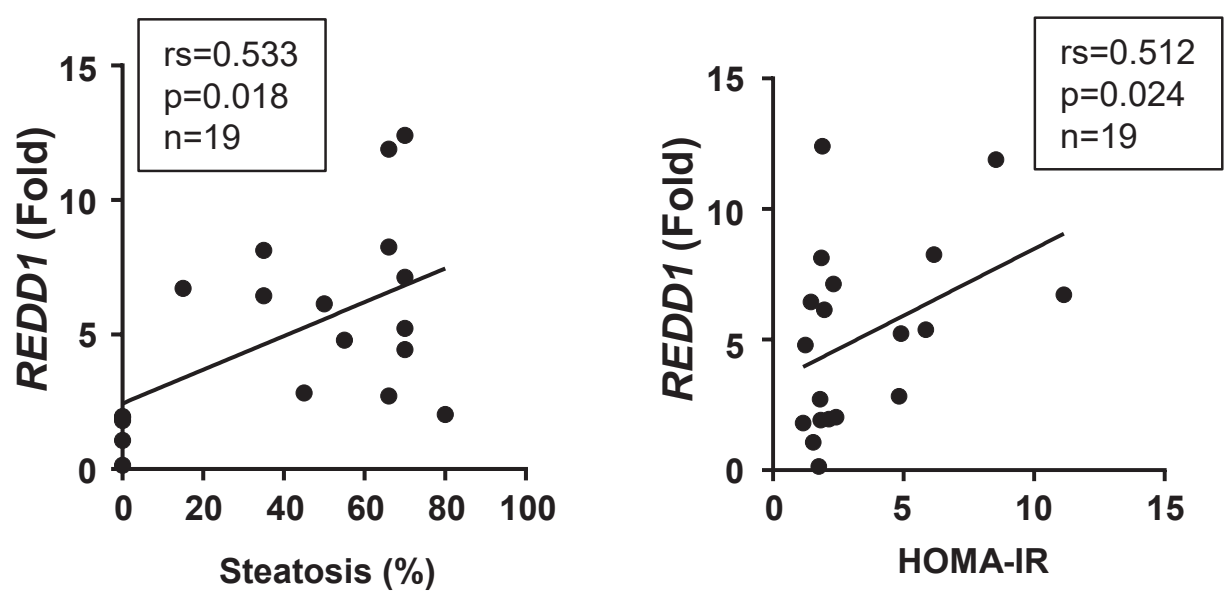
A.

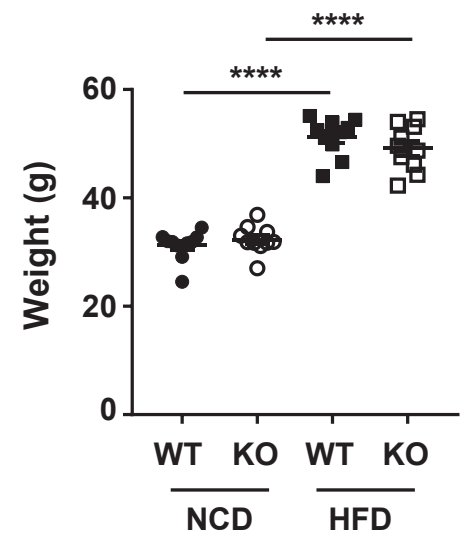

D.

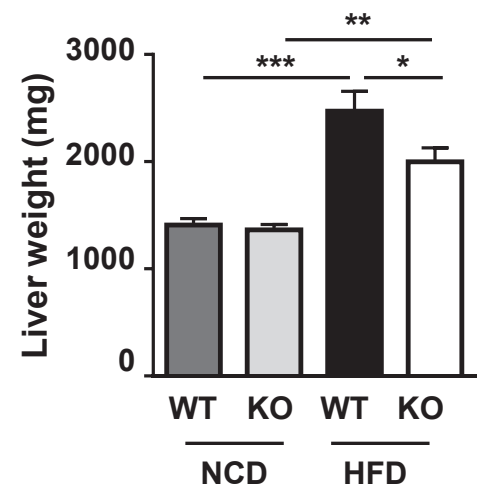

G.
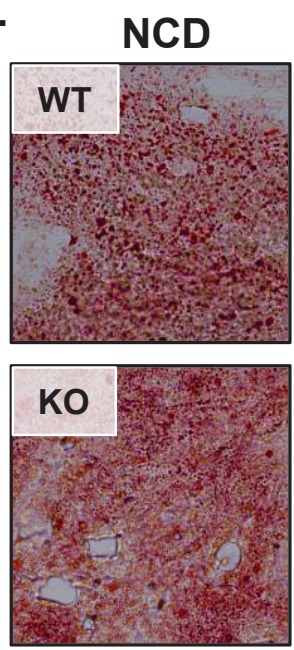

I.

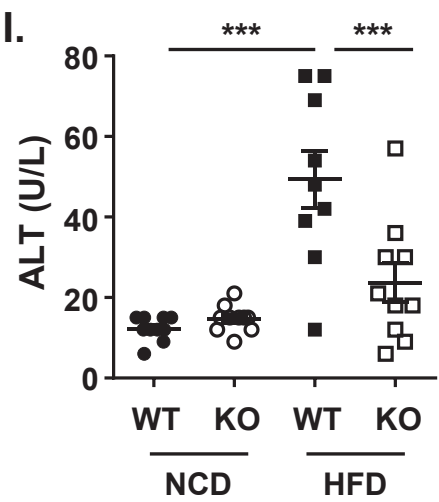

B.

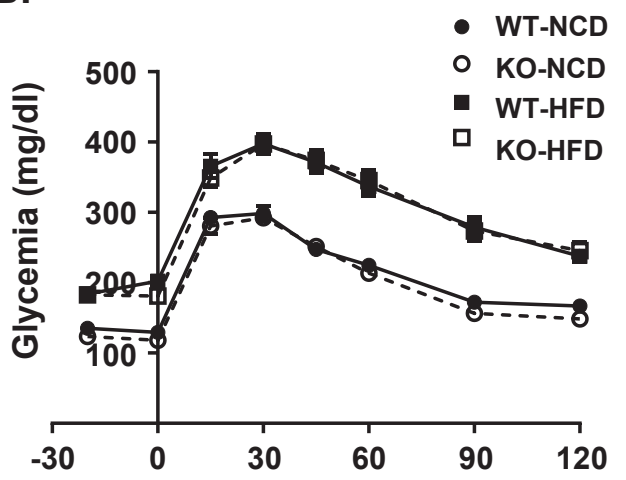

E.

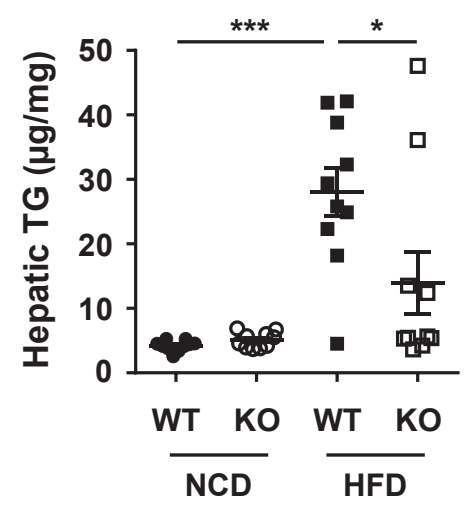

Dumas et al. Figure 2

c.

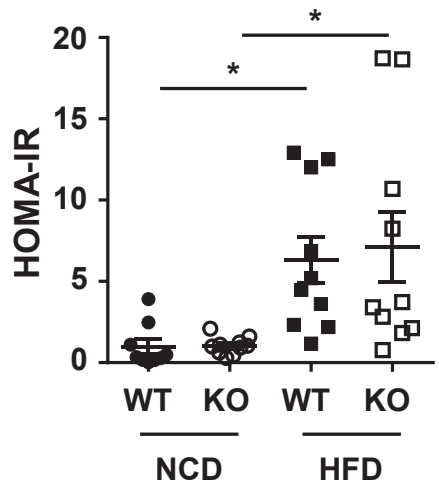

F.

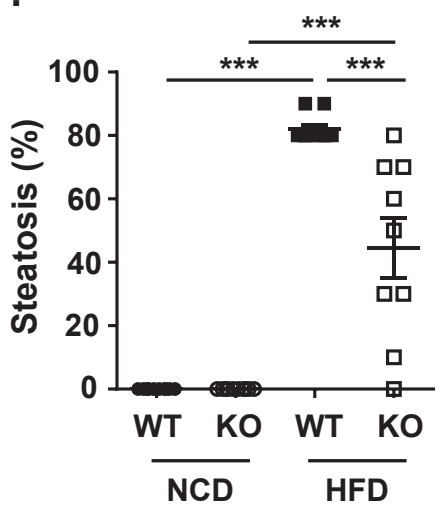

HFD $H$.
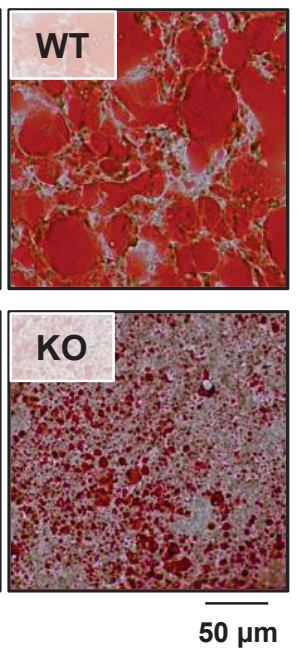

J.

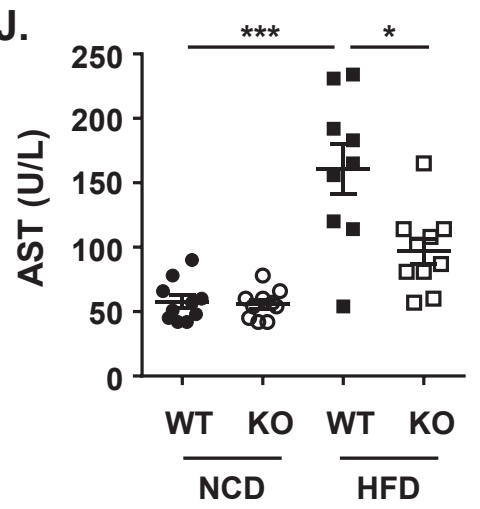

H. NCD
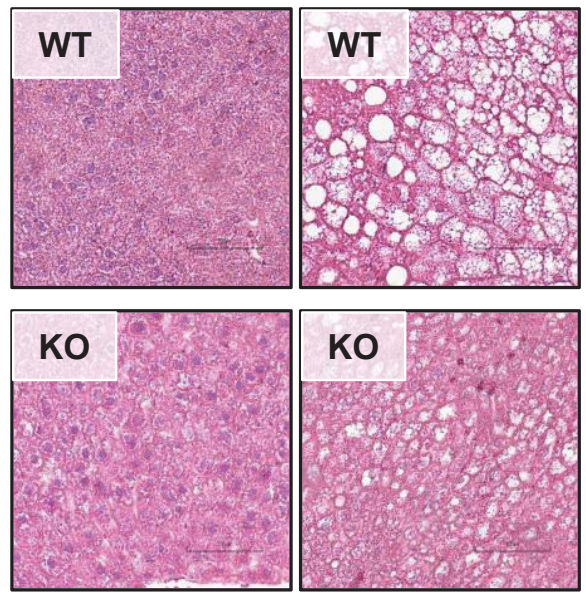

$100 \mu \mathrm{m}$

$\mathrm{K}$.

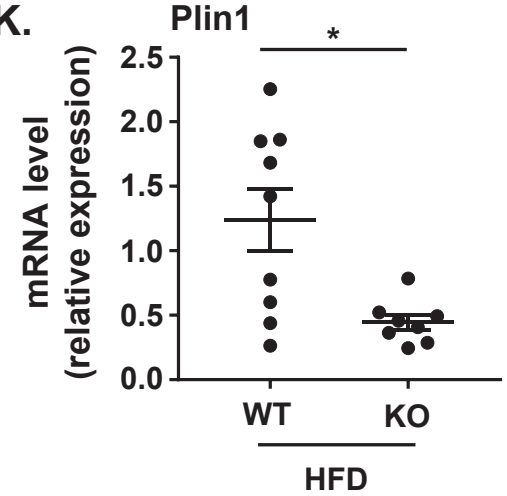


Dumas et al. Figure 3
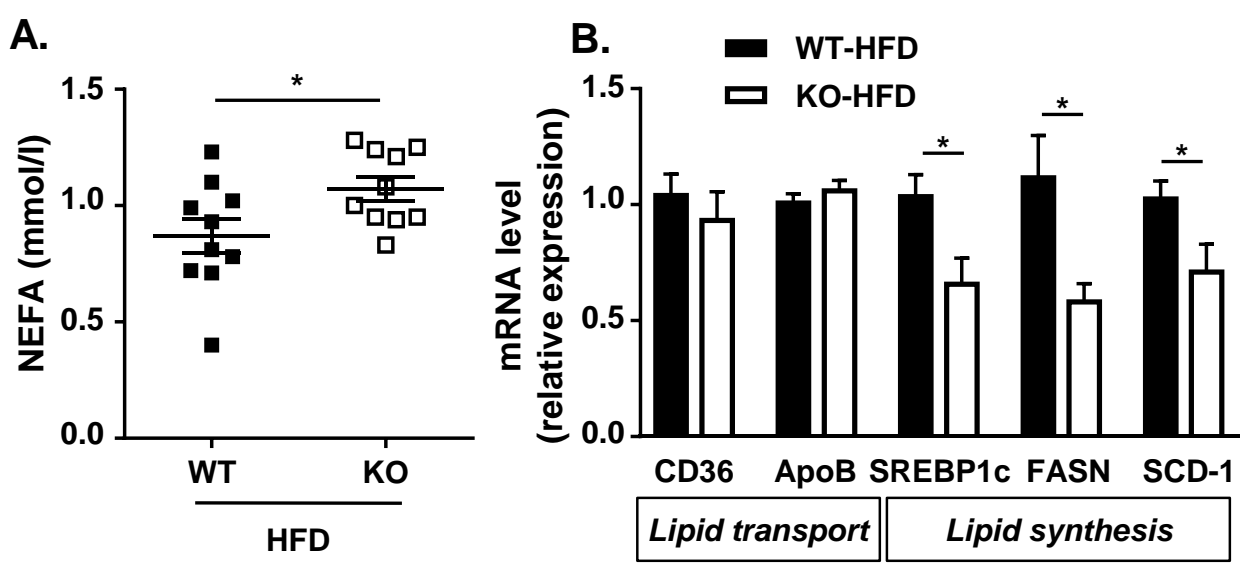

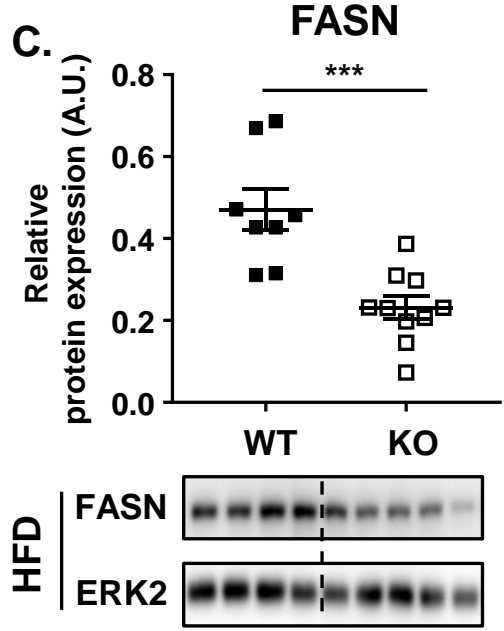

D.

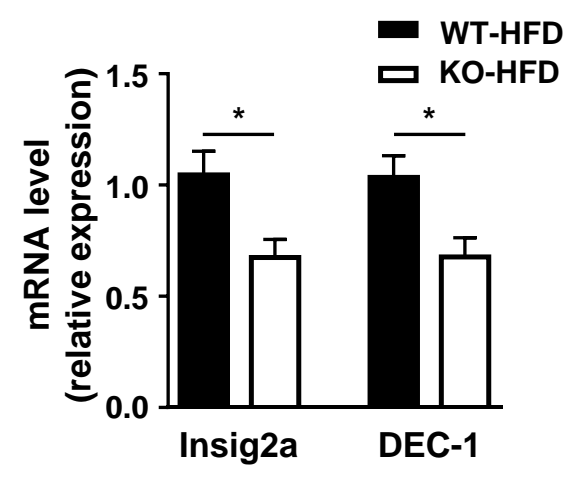

E.
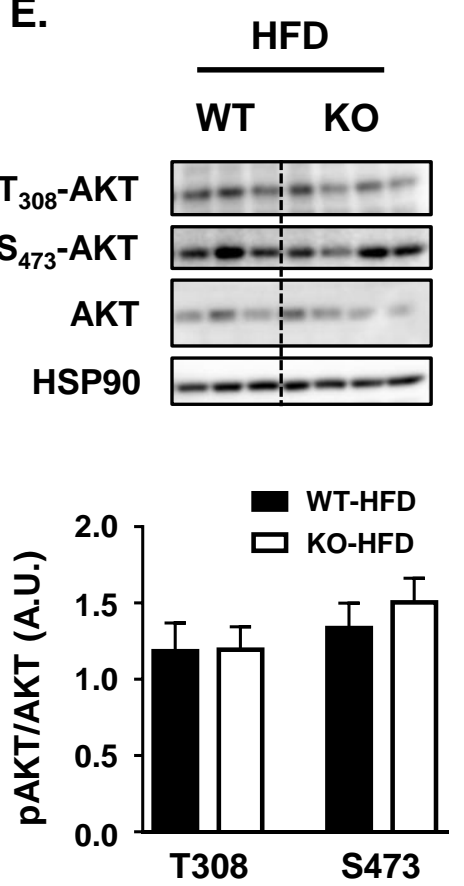

F.
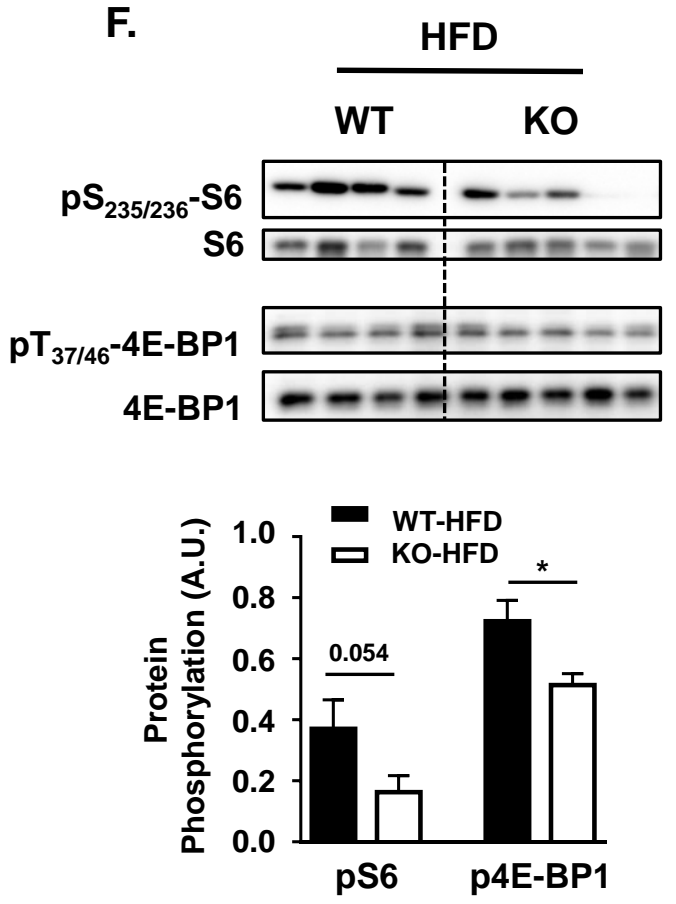
A.

HFD

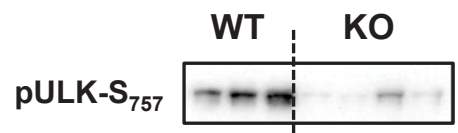

B.

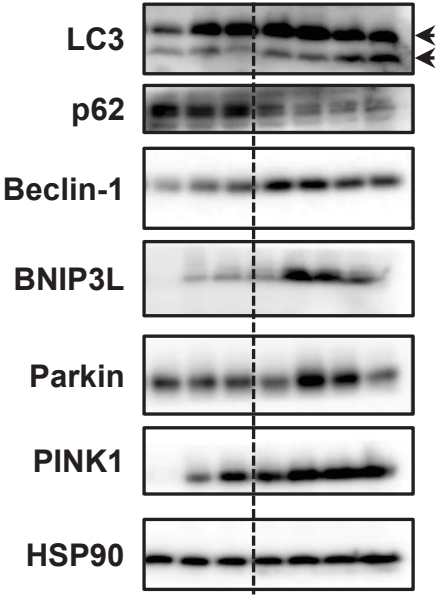

C.

NCD
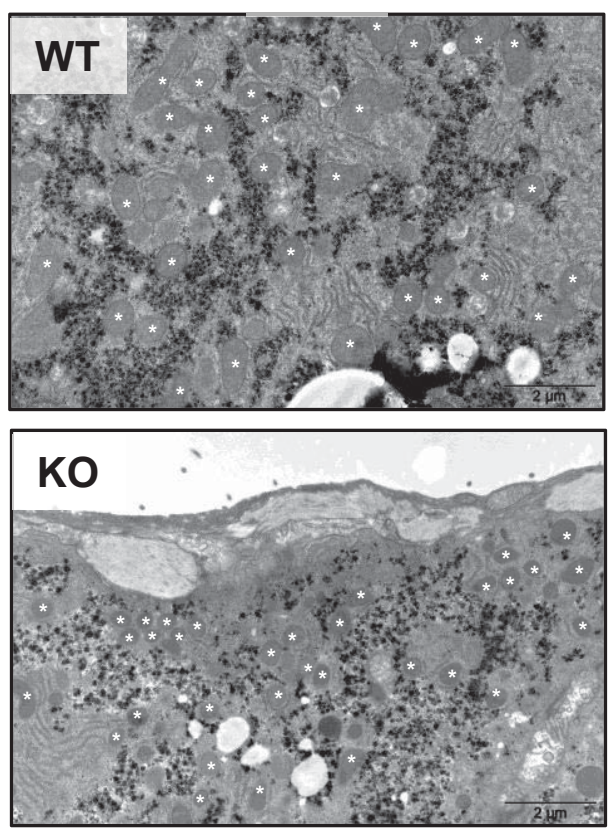

F.

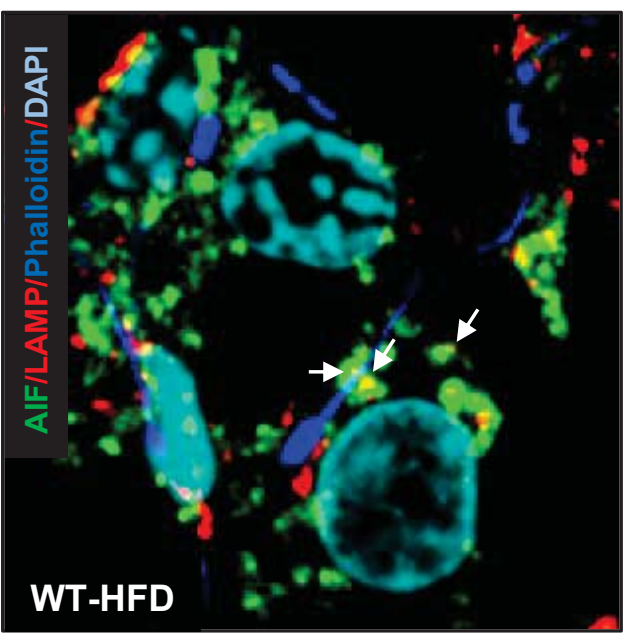

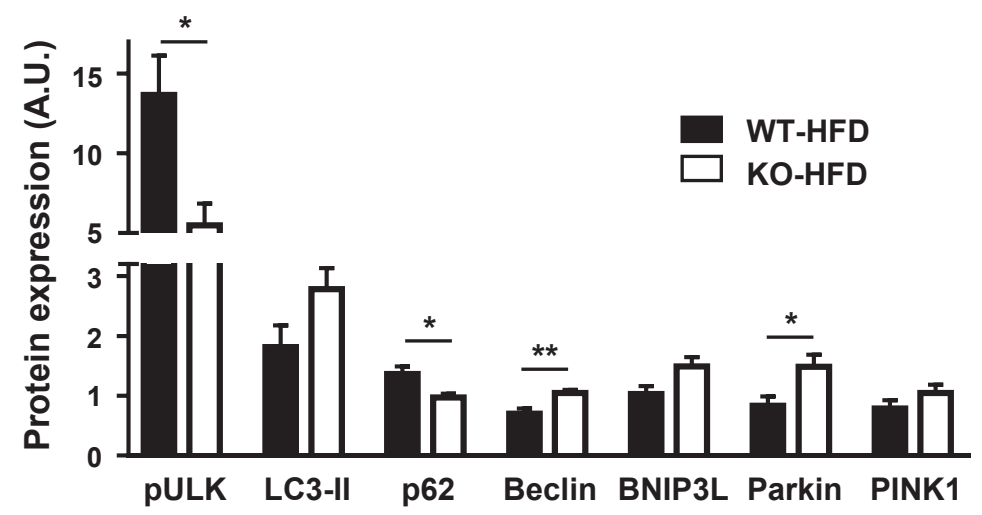

Dumas et al. Figure 4

D

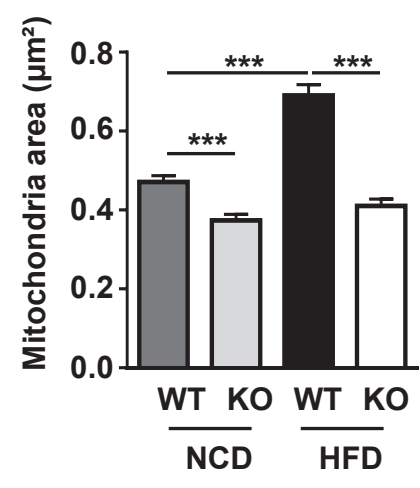

E.
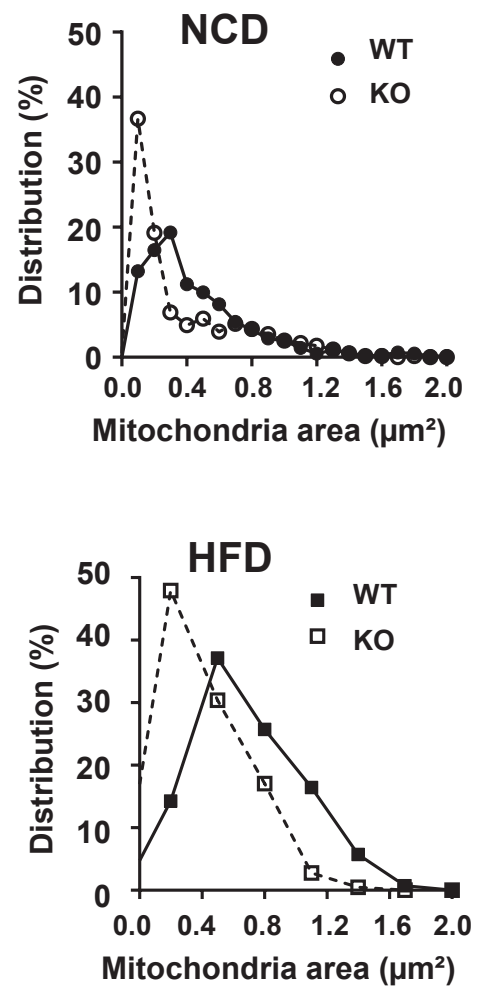

G.
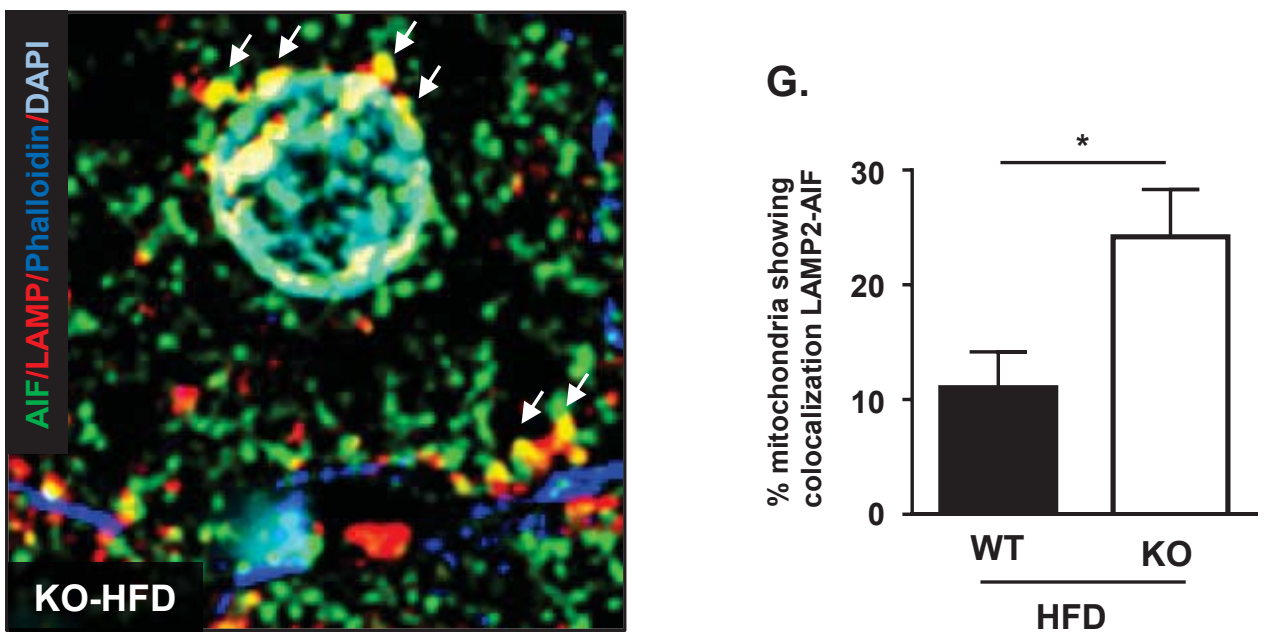
A.

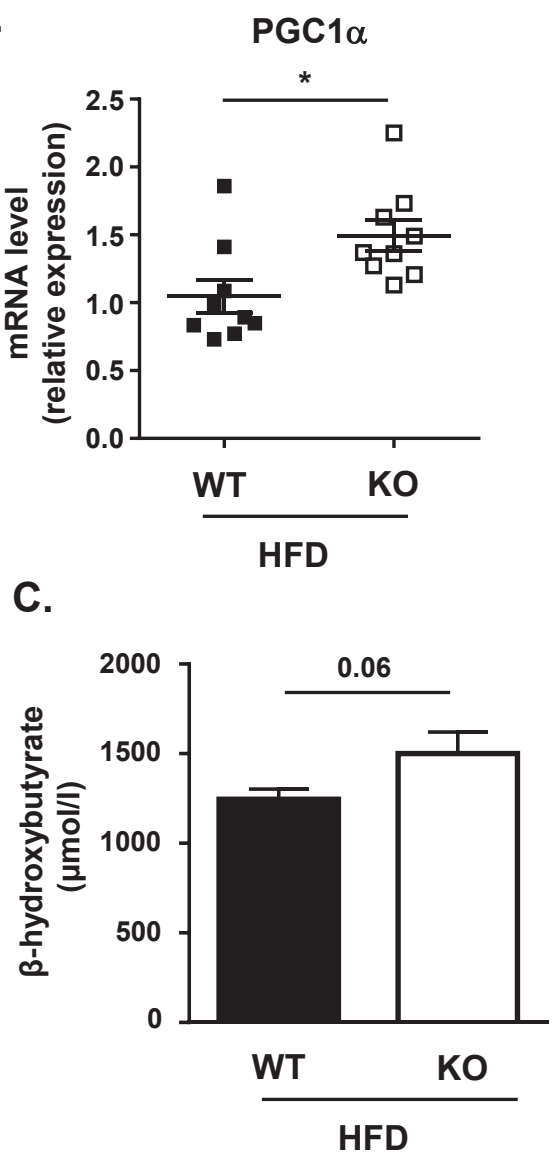

B.

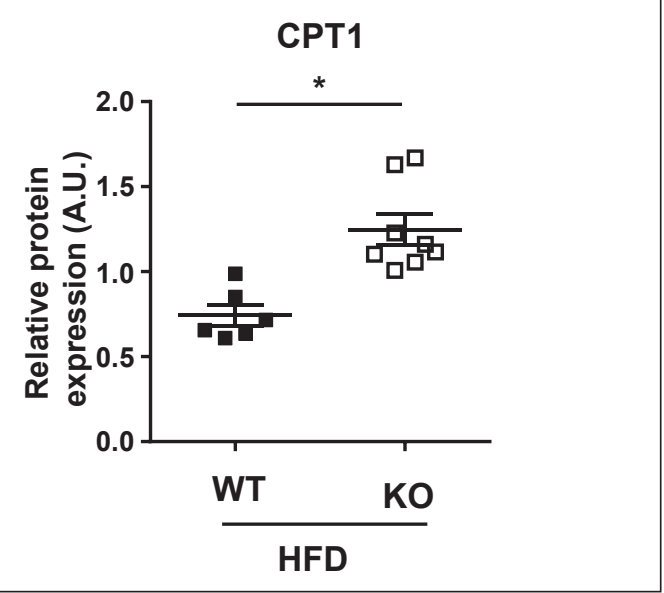


A. REDD1

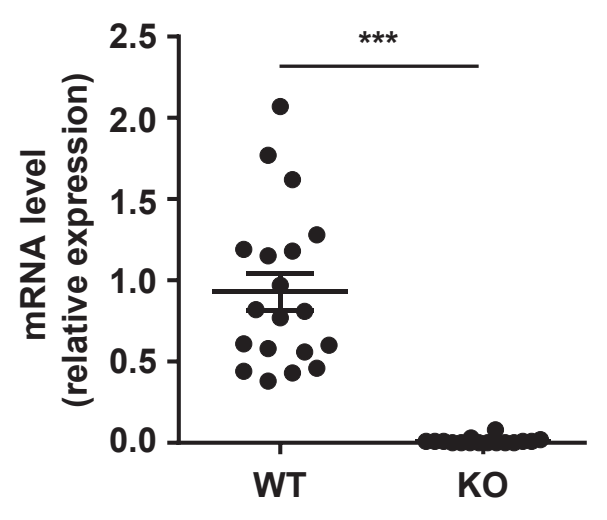

B.

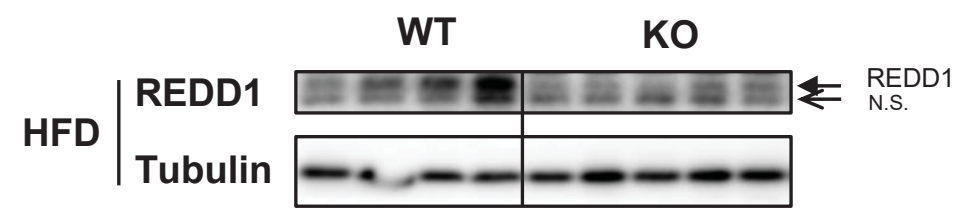

Supplemental Figure 1: REDD1 expression level in liver of WT and REDD1KO

(A) Expression of REDD1 was analyzed by RT-qPCR in liver of WT and REDD1KO mice (WT: $n=19$; KO: $n=16$ mice/ group) or (B) by immunoblot (each lane correspond to one mouse). 
A.

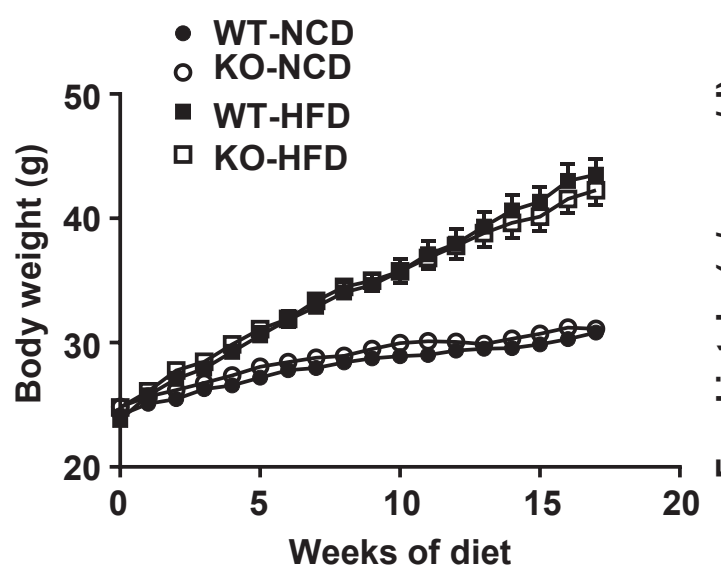

B.

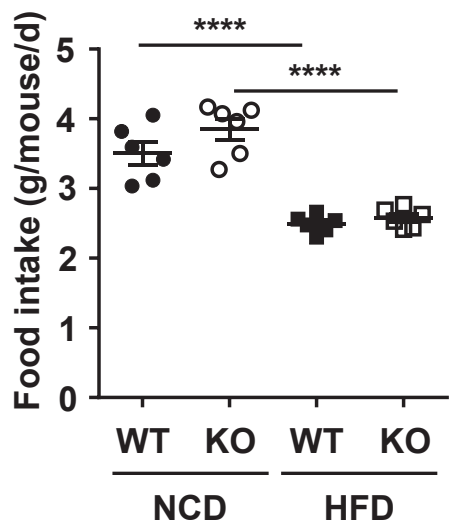

C.

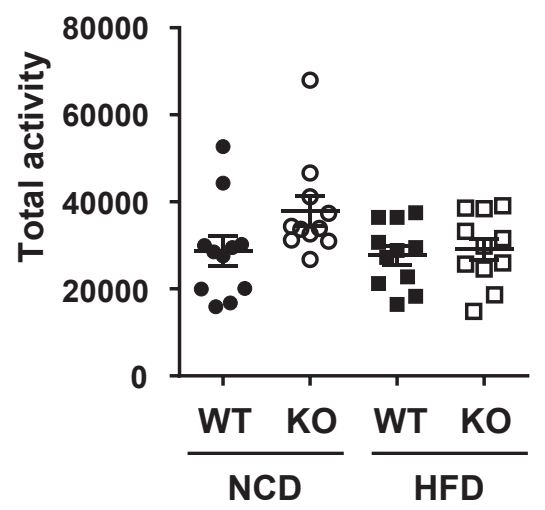

D.

NCD

HFD
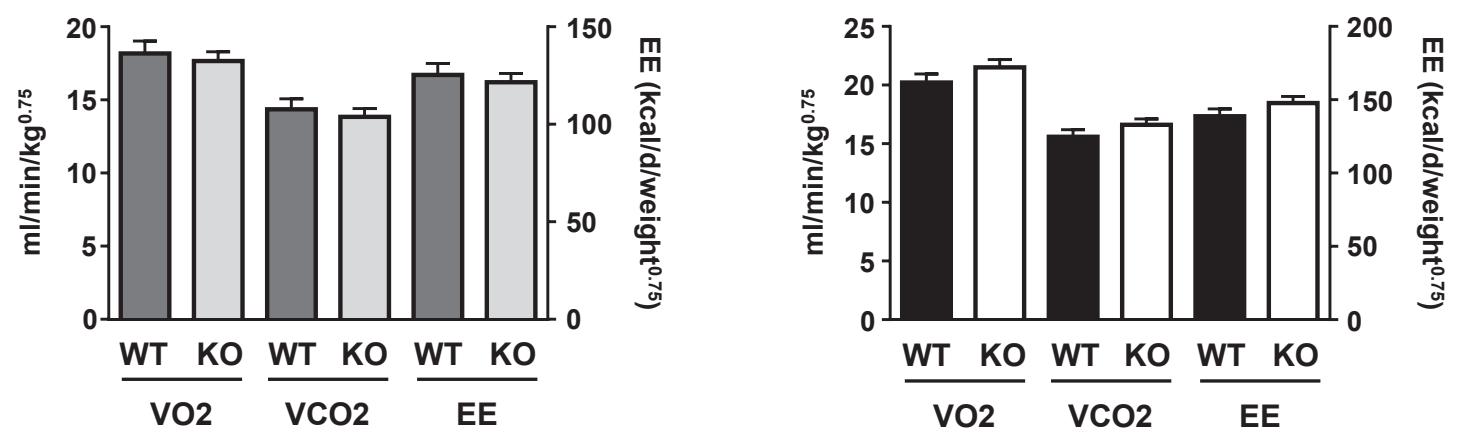

E.
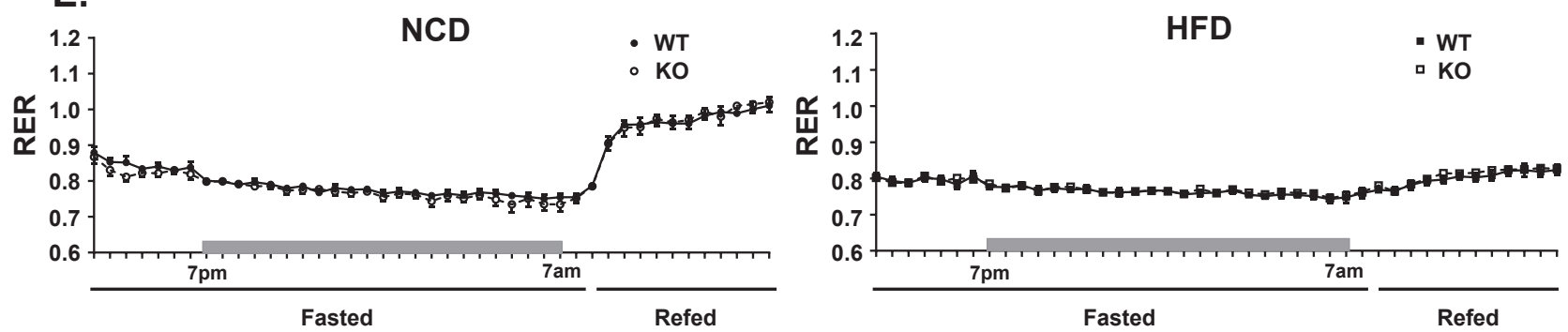

F.
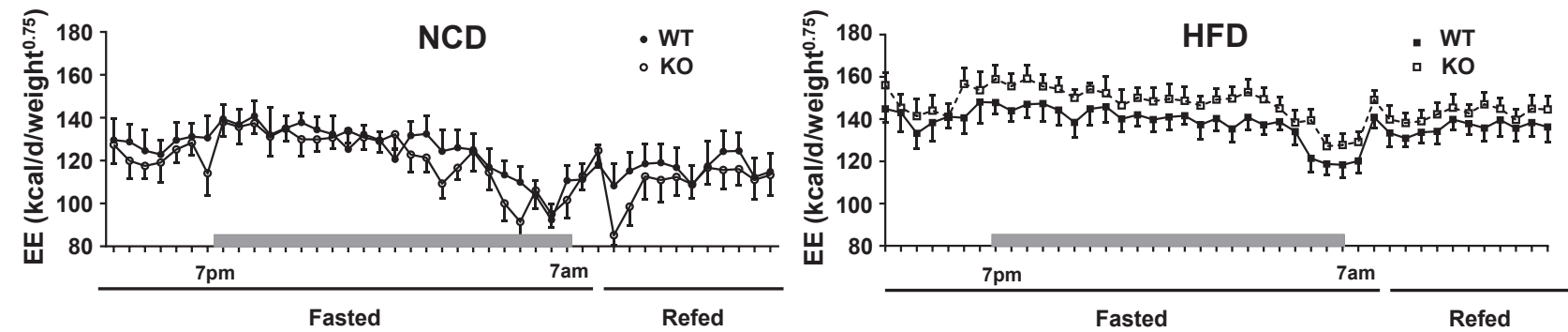

Supplemental Figure 2: Metabolic characterization of WT and REDD1-KO mice

(A) Weight of WT and REDD1-KO mice during diet exposure (WT: n=22; KO:n=24). (B) Food intake of WT and REDD1-KO mice ( $n=6$ cages). (C) Total activity for 48 hours recorded by metabolic cages $(n=12)$.(D) VO2, VCO2 and energy expenditure (EE) of WT and REDD1-KO mice fed with NCD or HFD. (E) Respiratory exchange ratio and (F) Energy expenditure of WT and REDD1-KO mice fed with NCD or HFD $(n=12)$. 
A. Fasted insulinemia

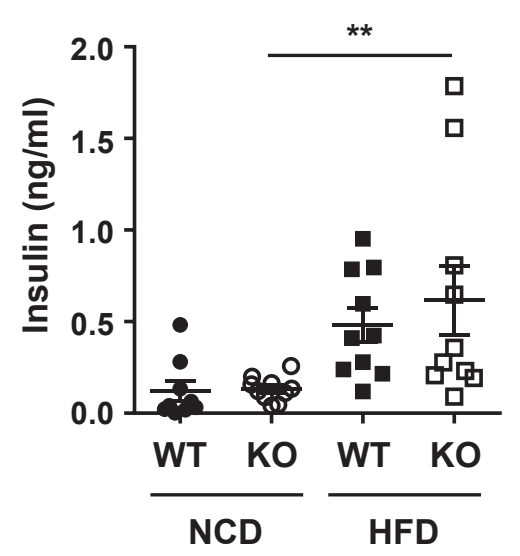

C. Fed insulinemia

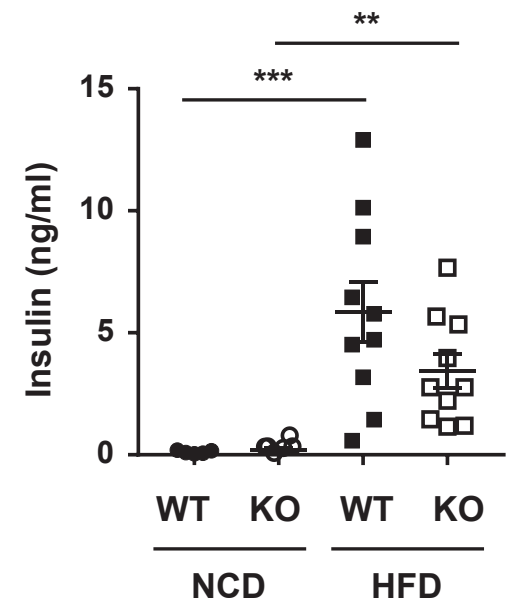

F.

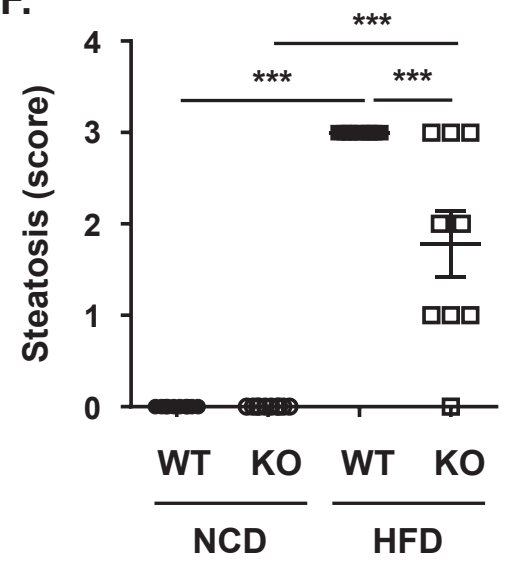

B. Fasted glycemia

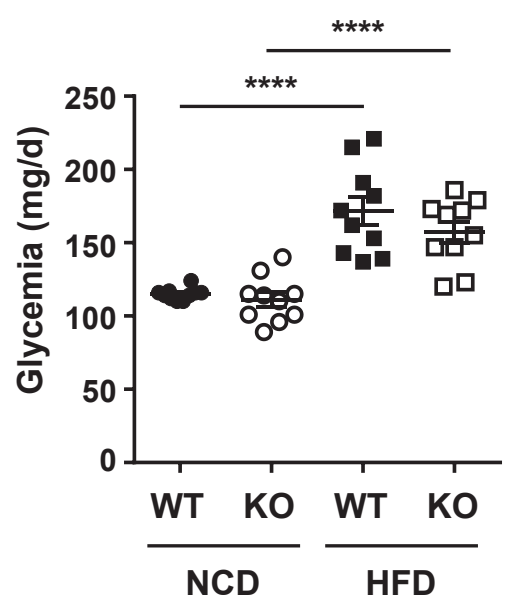

D. Fed glycemia

E.
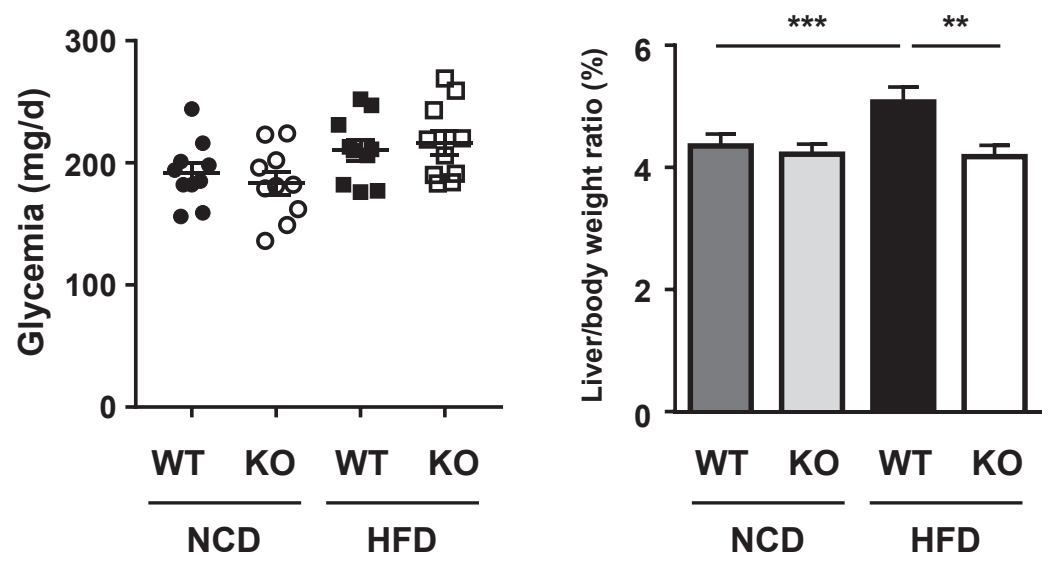

G.

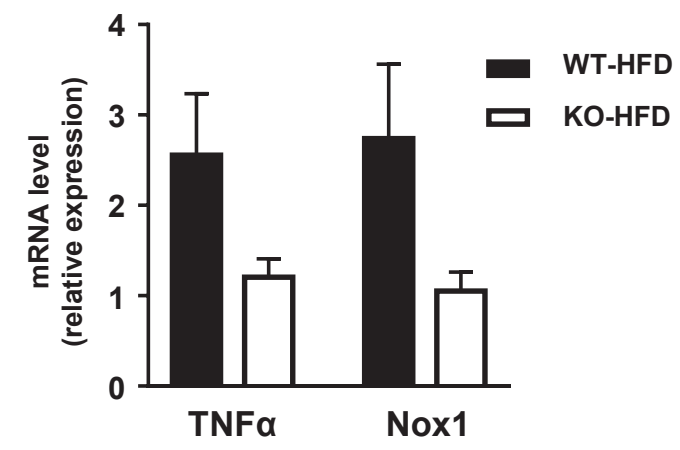

Supplemental Figure 3: Metabolic characterization of WT and REDD1-KO mice

Fasted (16 h) (A) insulinemia and (B) glycemia and (C) fed insulinemia and (D) glycemia of NCD- and HFD-fed WT and REDD1-KO mice (E) Liver/body weight ratio after 25 weeks of diet $(F)$ score of steatosis from H\&E staining of liver tissue( $n=9-10$ mice/group) (G) mRNA level in liver of NCD-fed WT and REDD1-KO mice ( $\mathrm{n}=10$ mice/group, relative expression compared to WT-HFD) 
A.
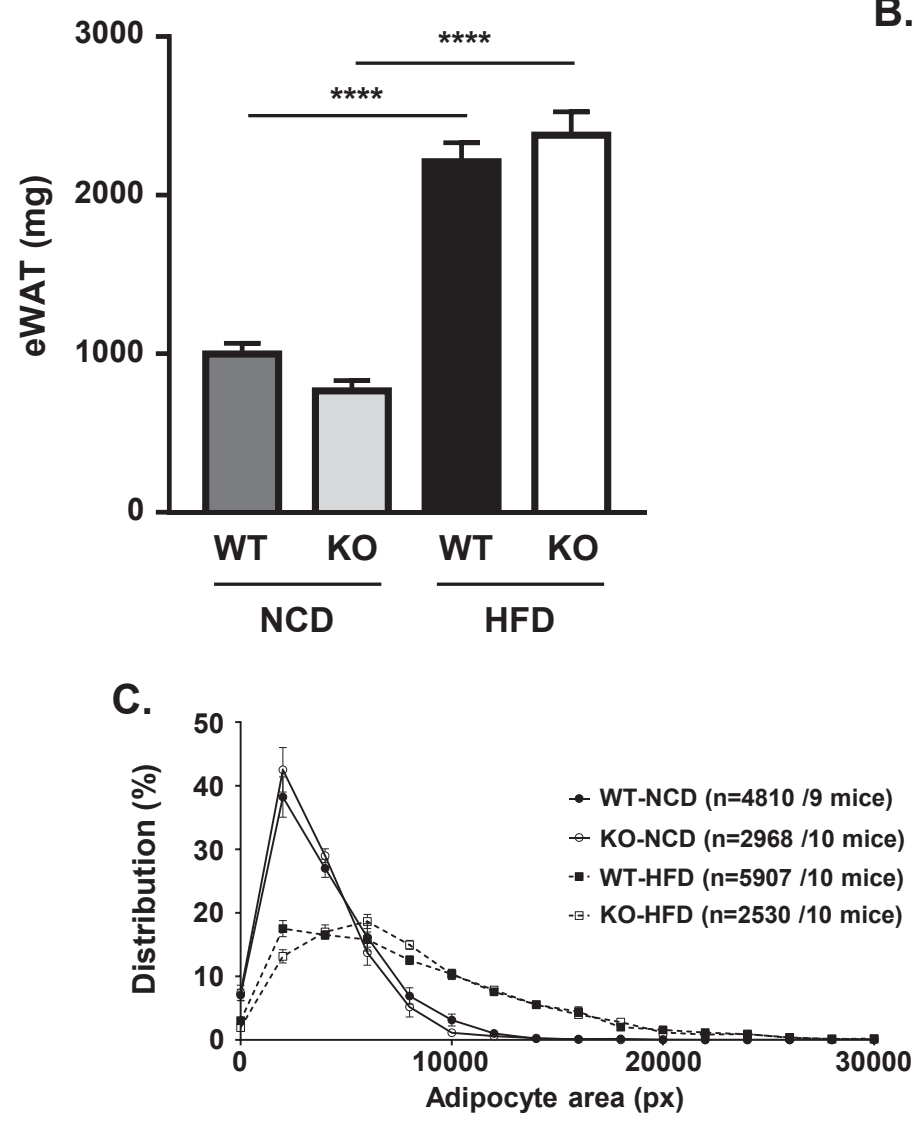

B. NCD HFD

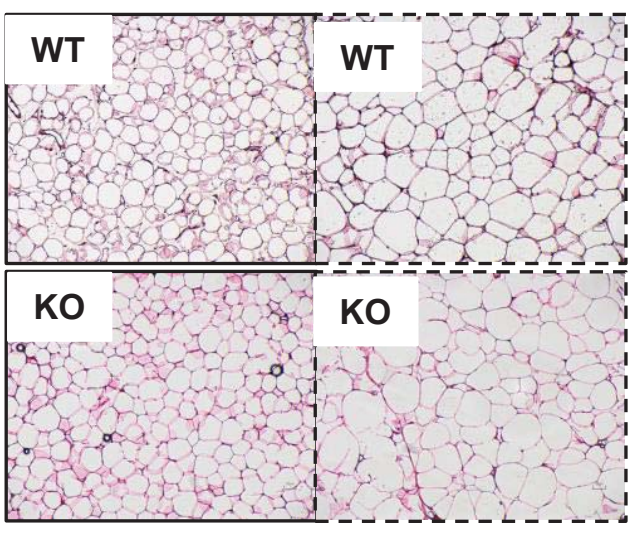

D.

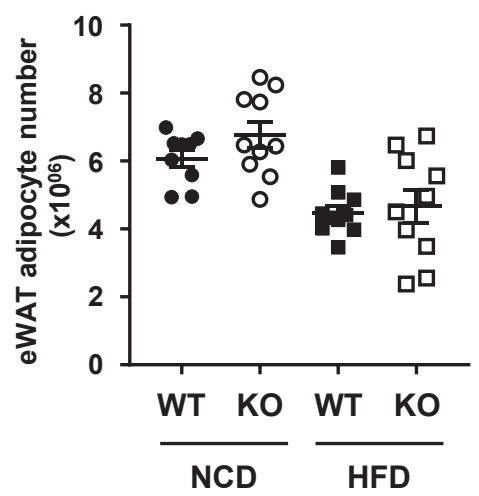

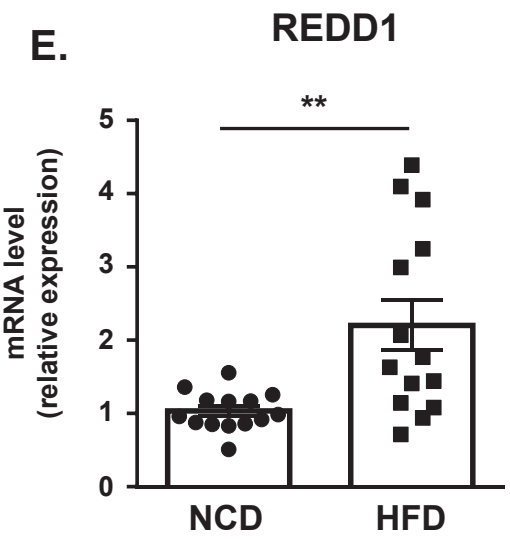

F.

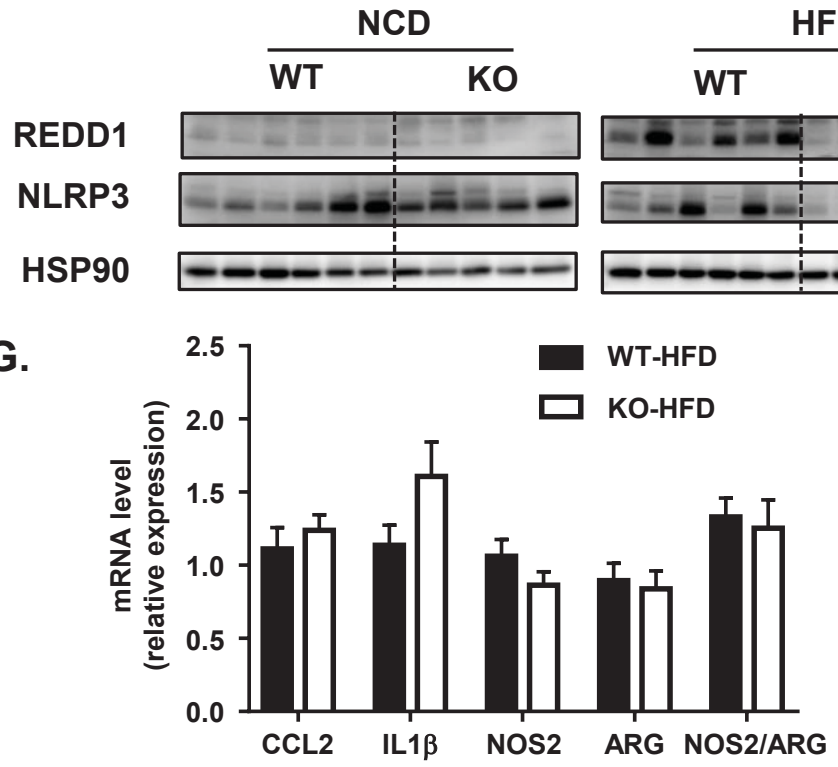

Supplemental Figure 4: REDD1 deficiency does not affect epidydimal adipose tissue

(A) Weight of epidydimal white adipose tissue (eWAT) of WT and REDD1-KO mice fed with normal chow diet (NCD) or high fat diet (HFD); (B) Picture of eWAT stained with H\&E; (C) Distribution of adipocyte size in eWAT; (D) number of adipocytes in eWAT=(mass/(density $\times(4 / 3) \times$ pi $\times \mathrm{r}^{3}$ ); (E) REDD1 mRNA expression in NCD- and HFD-fed WT mice; (F) Immunoblot of proteins of eWAT with indicated antibodies (each lane correspond to one mouse); $(G)$ mRNA level in eWAT by RT-qPCR (13 mice/ group), relative expression compared to WT-HFD. 
A.

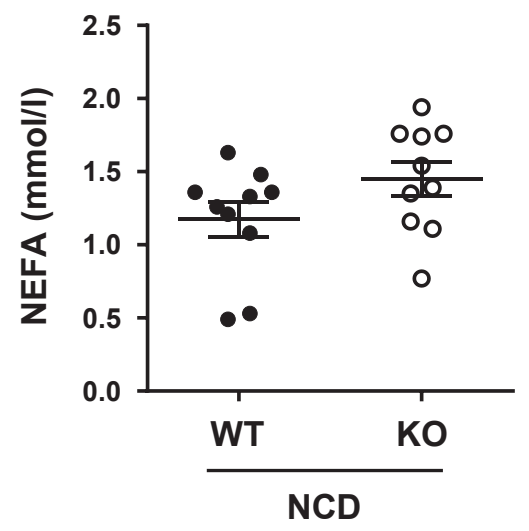

C.

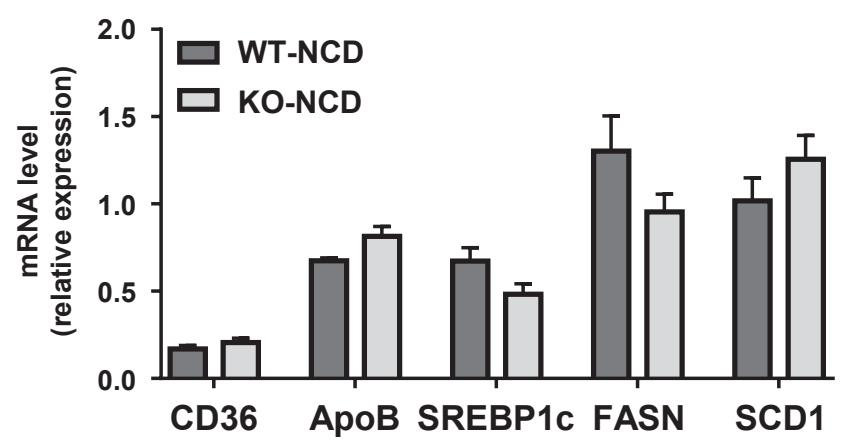

E.

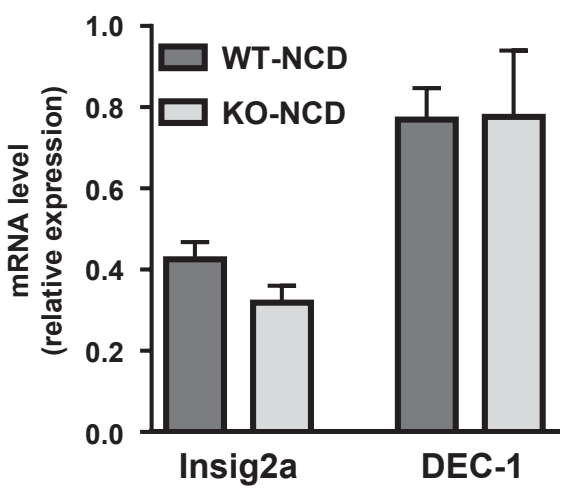

B.

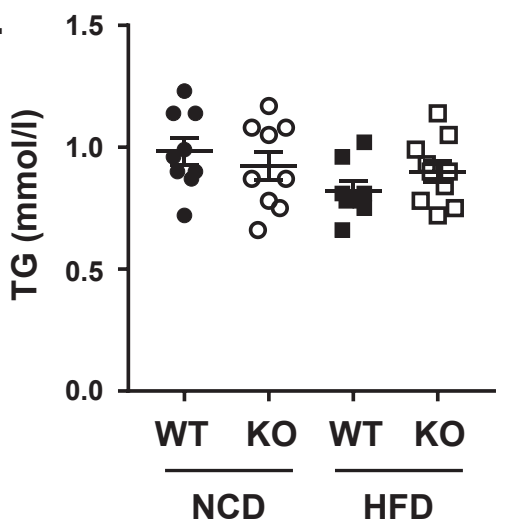

D.

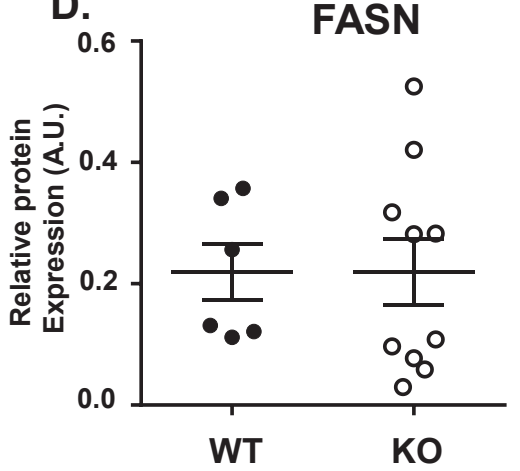

FASN

ERK2

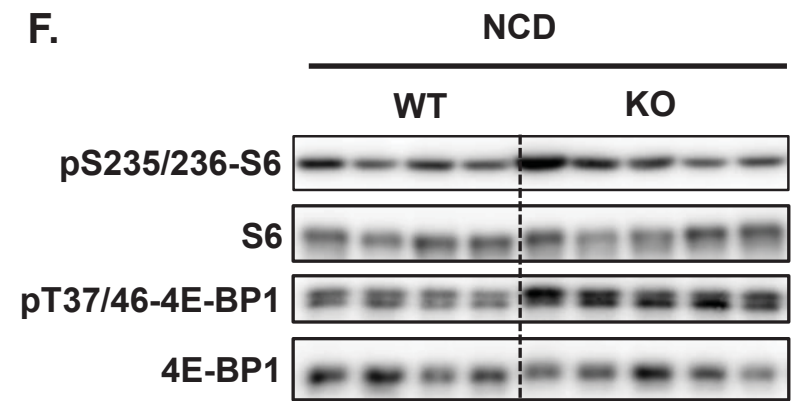

Supplemental Figure 5: Effect of REDD1 deficiency on circulating NEFA and triglycerides and lipogenic pathway in liver of normal chow diet-fed WT and REDD1-KO mice

Circulating levels of (A) NEFA and (B) TG in fasted NCD-fed WT and REDD1-KO mice ( $n=10$ mice/group) after 14 and 23 weeks of diet respectively. (C) mRNA level in liver of NCD-fed WT and REDD1-KO mice ( $\mathrm{n}=10$ mice/group, relative expression compared to WT-HFD). (D) Immunoblot of FASN in liver of NCD-fed WT and REDD1-KO mice. Quantification of relative expression (using ERK2 as loading control) (WT $n=6$ mice/group, $\mathrm{KO} n=10$ mice/group). Representative blot is shown (each lane represents one mice). (E) mRNA level in liver of NCD-fed WT and REDD1-KO mice ( $n=10$ mice/group, relative expression compared to WT-HFD). (F) Immunoblots in liver of NCD-fed WT and REDD1-KO mice. Representative blot is shown (each lane represents one mice). 

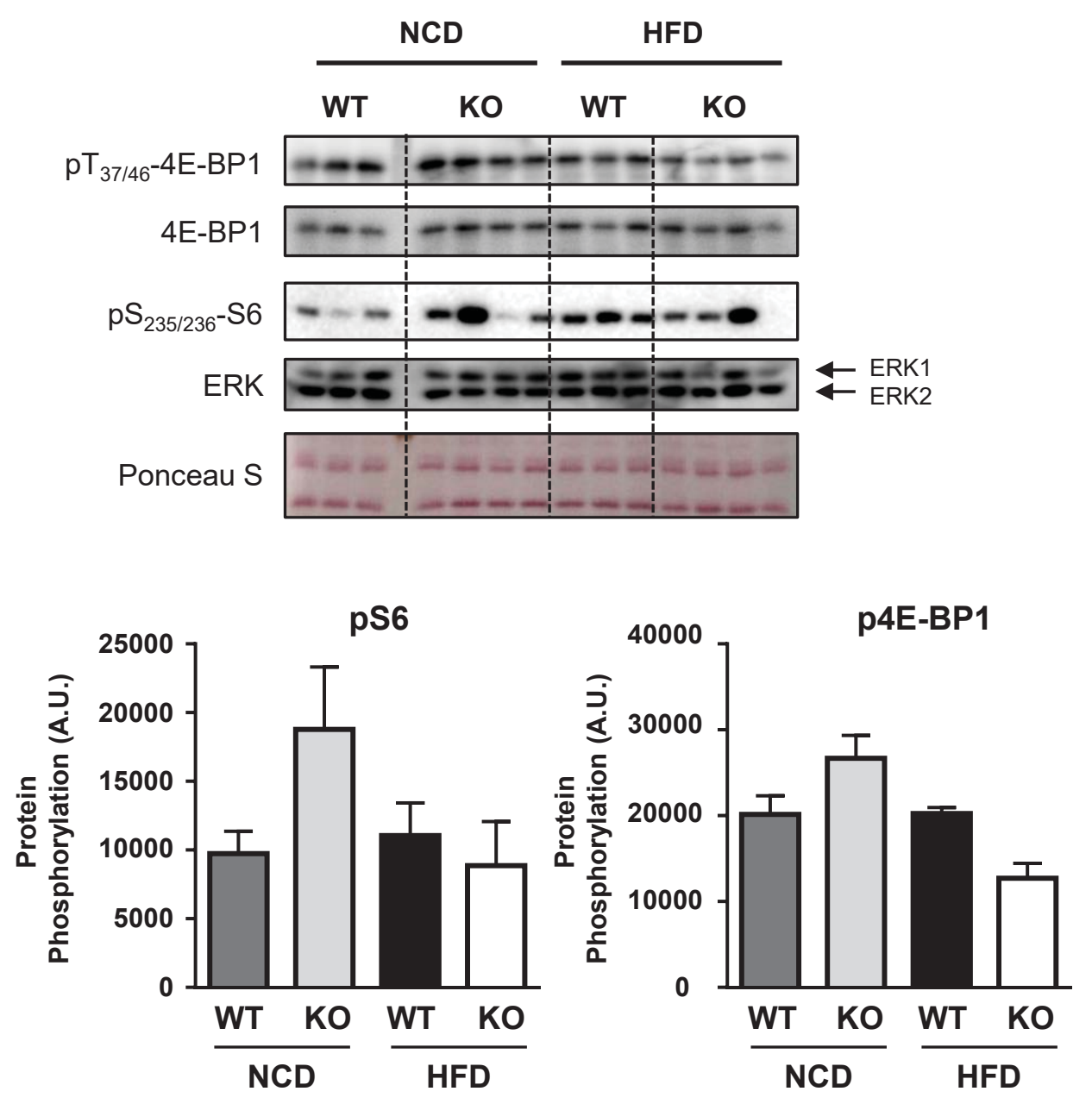

Supplemental Figure 6: Effect of REDD1 deficiency on mTORC1 signaling pathways in skeletal muscle of WT and REDD1-KO mice

Immunoblots with indicated antibodies in skeletal muscles of NCD and HFD-fed WT and REDD1-KO mice. Quantification of relative expression (using ERK as loading control) (WT n=6 mice/group, $\mathrm{KO} n=8$ mice/group). Representative blot is shown (each lane represents one mice). 
A.

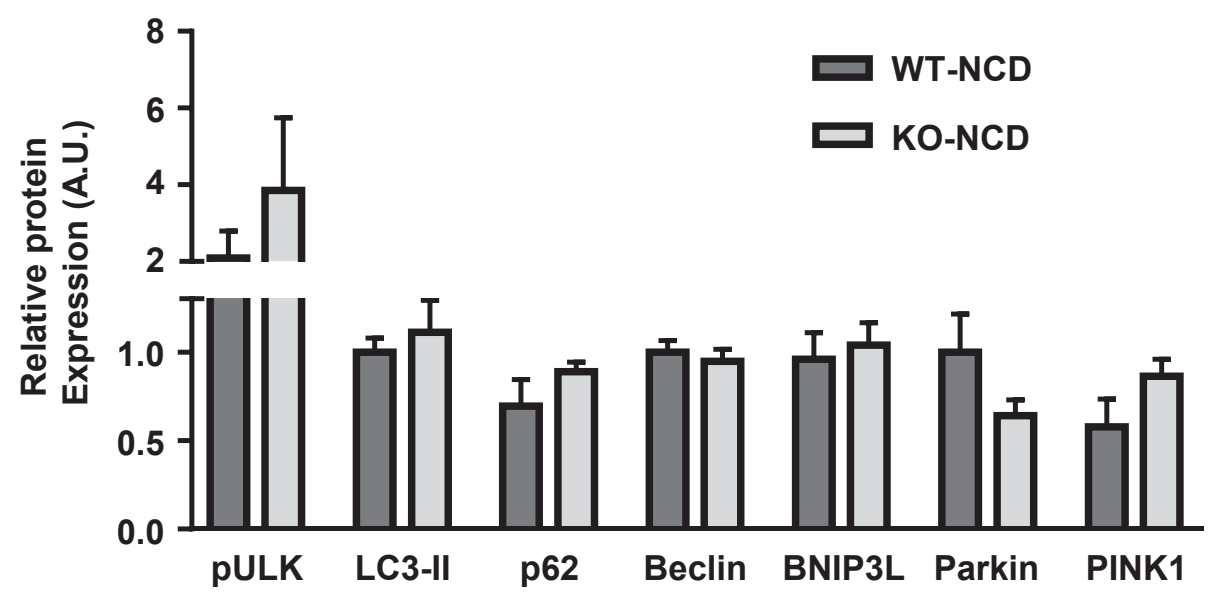

B.

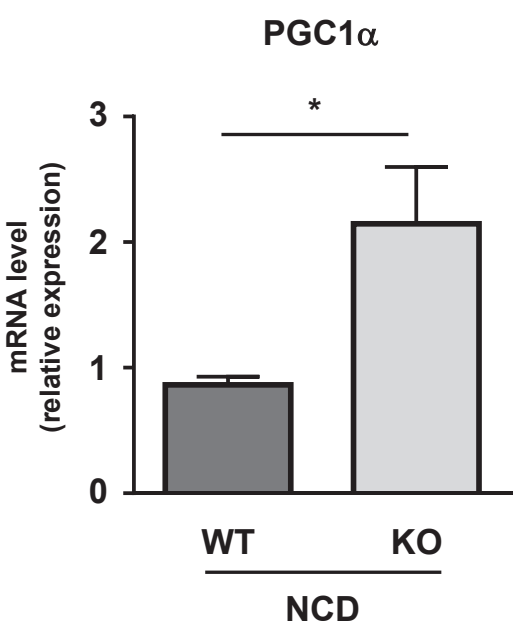

C.

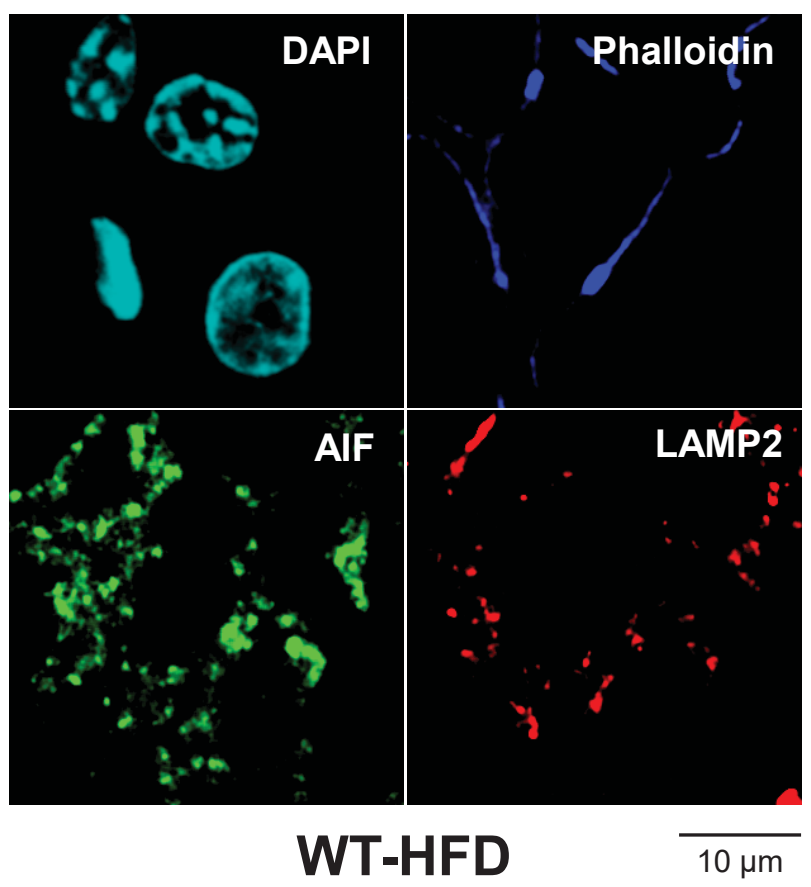

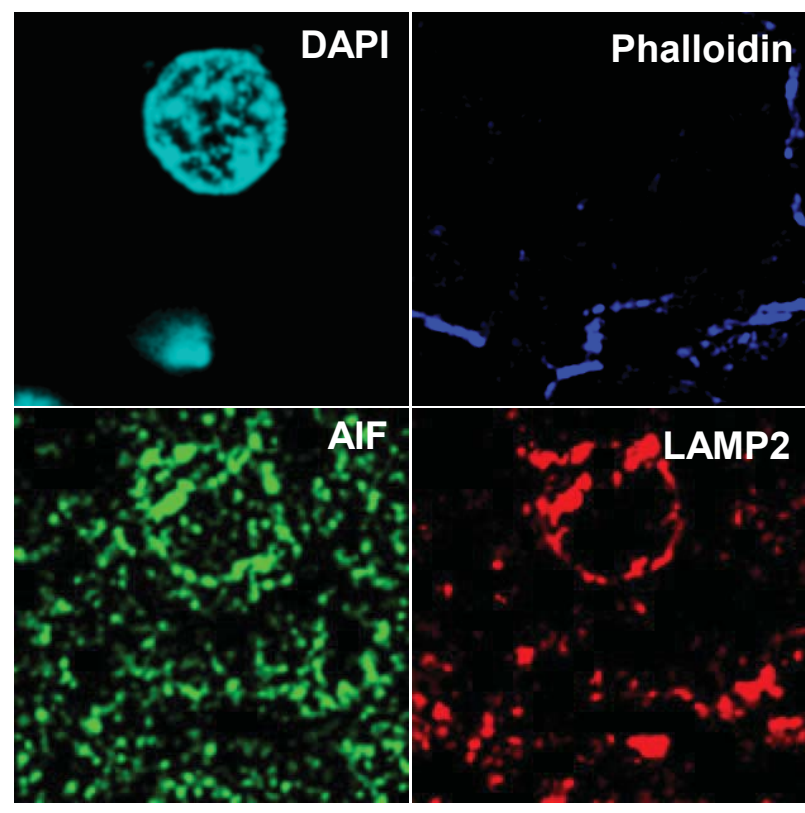

KO-HFD

Supplemental Figure 7: Effect of REDD1 knockout on the expression of markers of autophagy and lipid oxidation

(A) Protein expression (normalized by HSP90) in liver of NCD-fed WT and REDD1-KO mice (B) mRNA level in liver of NCD-fed WT and REDD1-KO mice ( $n=10$ mice/group, relative expression compared to WT-HFD) (C) Confocal microscopy of liver sections using indicated antibodies (correspond to Figure 4F). 